\title{
Some Notes on the Working of Superheater Locomotives with Special Reference to Lubrication.
}

\author{
Paper Read bejore the Institution by J. $H$. RIA, Member, Hechita, \\ Arfentine Republic, October 20th, 1917.
}

PAPER No. 55.

Although the Author has not had the privilege of reading the papers on the Lubrication of Locomotives and Superheaters, published in previous issues of the Journal of the Institution, in all other articles on the subject which have come into his hands he has been struck by the absence of discussion on the respective merits of sight feed and mechanical lubrication as applied to the fore ends. Efficient crlinder and value lubrication was admittedly one of the most important problems confronting locomotive engineers adopting superheated steam; and contemporaneously with the use of the latter the mechanical Jubricator sprang into prominence and was generally accepted as the only solution of the difficulty.

With engines using saturated steam the hydrostatic lubricator had for many years done its work efficiently. How did it come about that an apparatus, simple, cheap, and reliable in action, and with no working parts, should be discarded in favour of an expensive mechanical device? It may be presumed that our leading locomotive men did not take such a step without due consideration of the problem and extensive trial of the two systems. The author is open to correction, but believes he is correct in stating that of our leading English railways the only one to adopt as standard the use of a displacement lubricator in conjunction with highly superheated steam is the Great Western, whose locomotives perform, on a very reasonable fuel consumption, what is probably, year in year out, some of th hardest work in the country. On his last trip to Europe he was favoured by Mr. Churchward with an engine pass for a round trip between Paddington and Exeter, going direct and returning via Bristol, and was much impressed by the 
free running of the three engines upon which he rode. In the light of experience he must admit himself an advocate of the displacement system, and trusts that a brief review of its claims as against the drawbacks of the mechanical system may give rise to a discussion which will be of value and interest, seeing that our leading members must possess a wealth of information on the subject based on practical experience, if they oare to favour the Institution with the benefit of it.

Of a series of 32 engines equipped with superheaters and mechanical lubricators at present in service on the Western Railwav of Buenos Ayres, one was fitted with a pair of our standard two-feed displacement lubricators, the cylinders being fed through the holes original'y used, and the valves at a point in the middle of the steam chest. These are piston valves with inside admission. Snifting valves work horizontally and require a light spring to make their normal position shut without impeding their free working while drifting. These engines, though officially classed as " mixed traffic," are used entirely on passenger work and bear the brunt of the heavy main line traffic. Their chief dimensions are as follows:-

Type, 2-6-o.

Cylinders, 2oin. by 24in. Walscheart gear. Pistors valves, roin.

Driving wheels, $5 \mathrm{ft}$. $8 \mathrm{in}$.

Heating surface, $1,4^{1} 5 \mathrm{sq}$. $\mathrm{ft}$.

Grate area, 23.60 sq. ft.

Boiler pressure, izolbs.

Superheater, 21 elements.

Weight available for adhesion, $44 \frac{1}{2}$ tons.

Weight in working order with double bogie tender. 3,500 gallons of water and 5 tons of coal; 97 tons 15 cwt.

The loads hauled at times total up to 17 bogie vehicles on a $5 \mathrm{ft}$. 6in. gauge; stops are frequent, maximum grade $I$ in 200 , and as station delays are more often than not excessive, an inclusive running speed of up to 40 miles an hour is not uncommonly necessary to maintain the overall schedule. Adding to this the fact that the line runs almost due east and west, and that the prevailing winds are north and south in a very open country, and also taking into account the modest dimensions of the locomotives, it will be appreciated that their duties are hard. It is under these conditions that the displacement Iubricator has been so successful. The engine is a great favourite with the men. 
There has been no attempt at reducing the consumption down to the lowest possible limit; on the contrary in fact. For each run in the link a definite amount of oil is allowed, and no departure from this practice has been made with the hydrostatic lubricator engine, but nevertheless the driver, on his own account, shows an economy of some 9 per cent. in cylinder oil. The fgures in pints per 100 miles are 1.95 in the case of the hydrostatic lubricator, and 2.13 in the case of the mechanical; approximately 70 per cent. of this is fed through the valves and the rest direct to the cylinders. The consumption will be considered very high compared with English practice, but the water is bad, and it is found to be more prudent to provide a generous supply of oil to the fore ends.

Putting aside all claims made by various firms for their respective appliances, the Author would now like to raise, with a view to discussion, a few points noticed in actual practice.

One of the worst troubles is that of a deposit on the valves, etc., known as carbonisation, which impedes free movement of the rings, and if allowed to accumulate to any extent produces a blow; this renders it necessary for the values to be frequently taken out and cleaned. I think it can be accepted that these products are not formed to any extent while the engine is running under steam, when, although to a small degree distillation may be caused under the high temperature of the steam chest, the steam acts as an atomising medium. Dealing exclusively for the moment with the mechanical system and what takes placc when the regulator is closed on approaching a station, the reduction of pressure behind the piston exhausts all the oil from the feed pipes in front of the retention valves, and results in sudden fooding of the cylinders and valve chests. This is frequently accompanied by a whiff of smoke from the snifting valves, and a strong smell of burned oil, which appears to show that in the absence of an atomising medium, a large mass of oil is suddenly subjected to a great increase in temperature, resulting in rapid distillation and the formation of unstable bye-products which produce spontaneous combustion, the products of which adhere to the exposed surfaces.

After nine months working with a hydrostatic lubricator the valves have not had to be cleaned once, which goes to prove that oil is being fed in constant quantities under all conditions, and also establishes the necessity for oom- 
plete atomisation of the oil before introduction to the steam chest to ensure complete distribution of the lubricant over all the surfaces. The carbonised deposits are noticed to be present chiefly at the top of the piston heads, diminishing in quantity as the distance from the oil feed hole increases, and this fact gives rise to the question as to how cold oil fed at one point of a piston valve ring can be expected to lubricate efficiently the rest of the surface of the ring, although this is greatiy assisted by the lubricated exhaust steam from the cylinder. Considering further what takes place when the regulator is closed, after the oil is exhausted from the feed pipes, the following conditions probably exist ; each charge of oil fed past the pump is drawn into the cylinders and valve chest, and lubricates the surfaces adjacent to the oil feed hole whilst starving the lower surfaces. In this case when the engine comes to a stand the pipes arc empty, and on restarting have to be pumped full again, and the engine runs some distance without any lubrication. These conditions are detrimental, for when running without steam, the hot dry surfaces require complete lubrication. They are in direct contrast to those conditions existing with the hydrostatic lubricator, in which the steam jet acts as a drifting valve with the regulator closed. During the stop particles of oil are being deposited on all the working surfaces, leaving the engine in the required conditions for smooth working on restarting.

There is also a rexed question as to the proper proportion of oil which should be fed to the cylinders as compared to the valves. Even reducing the cylinder feed to 3o per cent. of the total, the cylinders are, in the Author's opinion, excessively lubricated, and he would be glad to hear of the practice and experience of other members in this respect. While running under steam he does not think there is any doubt but that under normal conditions the direct cylinder feed could be cut out altogether, but it cannot be neglected while drifting; feeding direct only to the valves therefore necessitates:-

(a) The fitting of cylinder cups or suction lubricators, or

(b) An automatic valve worked off the regulator to open live steam to the cylinder lubricator on shutting the regulator.

Except when kept up to absolutely 100 per cent. efficiency $(a)$ is extravagant with oil and (b) would not give immediate lubrication, and pending further experience the author prefers to retain the independent feeds for the time 
being. It is very significant that a large firm manufacturing mechanical lubricators has now introduced an anti-carboniser for use in conjunction with their apparatus; this appears to the author to be in direct contradiction to the objects of mechanical lubrication and the advantages claimed for it.

There is a radical difference between the ways in which the two systems operate, i.e., the mechanical lubricator feeds a fixed amount of oil per revolution of the driving wheels, i.c., the feed varies directly with the piston speed; the hydrostatic lubricator feeds a fixed amount per minute until reset. The Author does not lose sight of the fact that mechanical lubricators are on the market with feed controls worked from the cab, but these are apparently but rarely used, and in any case are also in opposition to one of the points advocated for mechanical lubrication, in having everything out of the reach of the driver and absolving him of all anxiety. To consider the matter practically, suppose a locomotive running downhill or on level track under very easy steam at 60 m.p.h.; in a few minutes it may be exerting its maximum effort to breast a $\mathrm{I}$ in $\mathrm{I}(00$ grade at 30 m.p.h.: under these two conditions the fore end is receiving the same amount of oil per revolution with mechanical lubrication, and the author cannot reconcile himself to the correctness of this. With a displacement lubricator it would be receiving twice as much oil per revolution up the grade as on the level without any adjustment whatever. This surely is more nearly complying automatically with the engine's requircments; and the necessity for a feed variable at will is also most important where light waters are encountered.

The Author finds no trouble from loss of superheat owing to the jet of saturated steam and oil, and it is difficult to understand how this could be very appreciable, being fed through a $\frac{1}{2}$ in. pipe with $5 / 64$ in. choke, as against highly superheated steam through a $4 \frac{1}{2}$ in. pipe, i.e., one of roughly 3,200 times the cross sectional area of the other. If it were existent to a prejudicial extent, although perhaps not registered through inaccuracy of the pyrometer, it would tell in the long run on the water consumption. It would also be present with the anti-carboniser in conjunction with the mechanical lubricator. Regarding this latter appliance, the Author has up to the present not had one under his personal supervision, and would be much interested if any member could state his experience of it. When the engine is drifting it is all right, but when the engine stops the steam jet is apparently still blowing into the fore end un- 
accompanied by oil, and it is on the effect of this that discussion is needed.

Turning now to the consideration of the position of the mechanical lubricator, this in itself is a very disadvantageous one in that, especially at night, the driver has no immediate indication if from any cause his lubricator stops feeding. Moreover, its exposed position, in a country where extremes of temperature are met with, causes difficulty in obtaining feed at a regular rate. On a run starting at midday at normal winter temperature and finishing at $6 \mathrm{p} . \mathrm{m}$. on a very cold evening, the Author has noted a difference in rate of feed of $4^{0}$ per cent. per 100 kilometres at the end of the run as compared with the start, running of course throughout without the steam heater for purposes of experiment. This shows that with cold oil the efficiency of the apparatus decreases with the temperature, and it decreases further with increase of speed, owing to a full charge of thick oil not having time to enter the pump in the short period of the suction stroke. The steam heater is applied to counteract this trouble, but the heater itself requires special handling to obtain uniform results, as even with this method of working and heating the oil at the bottom of the container, when running fast in a heavy frost, the air has a great cooling effect on the deposit, tending to reduce the temperature of the oil. This effect is at its maximum when the deposit is full and decreases directly as the quantity of oil. If the engine starts out at $6 \mathrm{a.m}$. in a heavy frost, and finishes at midday at normal winter temperature, at the start the heater might be required to be full open, but if left so, by midday when the deposit carried much less oil, this oil would be very much thinned and the feed too heavy. The heater, therefore, requires intelligent manipulation on the part of the driver.

Before leaving the subject of lubrication, it may be added that the hydrostatic lubricator used is the Detroit, and was selected for the trials. These lubricators were ready in stock, having been adopted some years ago as the B.A. Western standard for saturated steam engines. The oil is of a well-known English brand, and the mechanical lubricator of a good make.

With regard to the operation of superheater engines on the road, it would be of value especially to foreign members to hear if any special instructions are issued to drivers with regard to use of the regulator and reversing lever. Drivers here are urged to notch up as far as possible, to say 18 per cent. or 20 per cent. cut off, and to work the 
regulator as full open as they can without overrunning the schedule. Perhaps a simpler way of expressing this will be to say that where an engine will make running time on 35 per cent. cut off and half regulator, drivers are encouraged for preference to use more regulator, and the lever away back in the position in which they can keep schedulc time. Of course, it is not meant to be understood that the engines will keep time with loads of 17 bogie coaches at 18 per cent. cut off. There is great difficulty with the old Argentine drivers in this respect, for not only do they cling hard to old traditions, but they had for some years previously run compound engines.

In favour of full regulator and short cut off the Author adduces the following arguments :-

(a) Advantage is taken of the elastic properties of superheated steam, and of its power of long expansion without condensation and fear of choking in the restricted area of the exhaust ports at short cut off.

(b) To obtain pressure in the steam chest as nearly as possible approximating to that of the boiler, since it is a waste of energy to generate 17olbs. in the boiler, and throttle it down a high percentage before using it.

(c) By using small regulator opening the saturated steam from the boiler is wiredrawn before entering the superheater. On the other hand, with the short cut off there would be a tendency to increased wire-drawing through the admission ports, but before reaching these the steam is already at a high temperature, and not so susceptible to the trouble; and, moreover, the initial wire-drawing through the regulator is less.

(d) Better superheat is obtained for the following reason. Suppose the engine to be running at a certain speed at "full regulator," and cutting off at 20 per cent.; and suppose the regulator to be gradually closed, at the same time letting down the lever so as always to maintain the same speed. As the demand for steam, that is to say, the amount admitted to the cylinders is increased, the supply, that is the amount passing through the regulator, is decreased, and therefore the speed of the steam through the elements is increased. This obviously gives it less time to absorb heat, whereas conversely, with the regulator valve in position to supply all or more of the steam than the cylinders require, the steam is detained in the elements for a longer period with the benefit of increased final temperature. Slightly less water is therefore used and consequently less coal, and a further result of this 
is that the water lifts less in the boiler owing to the "draw off " of steam being slower, and this is very important on railways such as that with which the author is connected using light waters,

(e) A lighter draught is produced, but care must be taken to keep a light, bright fire or all the other advantages obtained may be considerably lessened.

We are now trying to dispense with damper gear, draught retarding apparatus, etc., and so far without the slightest trouble of any sort. When possible this practice is greatly to be recommended, if only on the score of inaking one complication less in the smoke box.

It is moreover desirable on engines working a service where stops are frequent, as a useful superheat is just reached when the dampers shut down and a good percentage of it is lost in stopping. There is a marked decrease in the fall of temperature in the header whilst standing in stations without the damper.

The sudden cutting off of the draught through the upper tubes when the regulator is shut and the diversion of the entire flow of gases through the lower tubes might be expected to cause an uneven rate of expansion and contraction as between the upper and lower rows, and therefore produce a stress in the tube plate.

Excessive pitting of the exterior surfaces of the elements has been a source of great trouble, which the author hopes may be partly eliminated with the disuse of the dampers. $\mathrm{He}$ is of the opinion that the greater proportion of the trouble occurs during lighting up, or during periods of rest when the gases containing sulphur compounds are allowed to condense on the surfaces having a reduced temperature with the liberation of sulphuric acid, i.e., in cases where such gases have entry to the large flue tubes, but no exit owing to the closing of the damper. 


\section{DISCUSSION.}

The President: This is a very interesting paper provocative of differences of opinion. It is unfortunate that Mr. Rea is not here for us to thank him personally, but the Secretary will write and thank him on behalf of the Institution.

I have only just seen the paper, so I will leave any remarks I have to make until I have had an opportunity of going into it a little more deeply. But it certainly should bring forth a very useful discussion, because the question of lubrication with superheaters is of very great importance. Moreover, the method of working on the part of the driver is also a subject that should bring forth some interesting information, since it is one of the debatable points in locomotive running.

With these introductory remarks I will now ask the members to discuss the paper.

Mr. Clayton, Member of Council (C.M.E. Dept., S.E. and C. Railway): This is a thoroughly practical paper; it is the record of actual experience, which we want, and it puts it in a very simple way.

The Author says he believes the Great Western Railway is the only one which has attempted to use sight-feed lubricators in conjunction with highly superheated steam. I believe that others here will bear me out in saying that the L. and S.W. Railway uses the sight-feed lubricator on its latest highly superheated steam locomotives, also that the type is the "Detroit," the one used by the Author, and I understand that good results are obtained. I have only a somewhat limited experience of it, but so far as I have seen the sight-feed lubricator is capulble of successful application to the highly superheated steam locomotive.

The chief trouble, as most railway people know, is carbonisation. That, as the Author has shown, probably takes place when the engine is drifting without steam. So long as steam is passing through the valves and cylinders nothing serious happens-the lubricant is largely carried along with the steam; but immediately the steam flow ceases the lubricant is still being discharged into the cylin- 
ders, and in my opinion two or three things happen just at this time. Oil is being mechanically forced into the steam chest against practically no pressure, and since there is no steam to emulsify the oil it is deposited on the surfaces near the points of admission and particularly where there is no flow of steam. Heat is drawn, either as steam or hot air, from the elements by the action of the pistons and valves which act like suction pumps, and since the surfaces are cooler because there is not the flow of steam through them. it results that there is a deposit of solids from the oil. Further, the piston valves act as suction pump plungers on the exhaust side, drawing the smokebox proalucts down the blast pipe. Tests of carbon taken from the bottom of the exhaust passages seem to prove beyond doubt that the deposits are very largely composed of particles of cinders.

The ideal principle of lubricating cylinders and ralves is, I think, that in which an atmosphere or emulsion of oil is created by lubrication of the steam as it enters the steam chest. This no doubt accounts for the success of the displacement or sight-feed lubricator working in conjunction with a jet of saturated steam highly charged with moisture which makes an oily emulsion.

Lubrication by means of a mechanical pump is, I think, a very questionable method, and probably only really successful where engines can be kept in the hands of the same driver or say a pair of drivers working similarly.

Some time agro it came under my notice that one of our drivets never seemed to get his engine (a superheater) carbonised at all, and the only reason to explain this was that he was in the habit, when drifting, of giving the engine just a little breath of steam, which seemed to keep matters right and is undoubtedly good practice.

The steam jet-or anti-carboniser as it is called-is not a new thing. Those who remember Mr. W. M. Smith, of the North Eastern Railway, and his snifting valve in which he arranged to have a little jet of steam when the snifting valve was open, will see the same idea. The steam jet used in conjunction with the mechanical lubricator is, I think, an advantage, and from the limited experience I have had of it the results are very satisfactory. It should not be left open when the engine is standing, and it is apt to be dangerous unless the cylinder cocks are left open, because the steam jet is still blowing into the cylinders, and, what is worse, it has the effect of spreading and depositing the oil left over the surfaces, making it most 
difficult to start or reverse the engine after standing two or three days, owing to the oil gumming or hardening.

I never can quite understand why a mechanioal lubricator was considered a necessary adjunct to the use of super-heated steam, but those who suggested highly superheated steam some years ago did certainly recommend as necessary a mechanioal lubricator, so that most people fitted it. This. brought other troubles in its train, and I think it is rather a pity that we did not go on with the improvement of the sight-feed lubricator and try to make it as great a success as the mechanical lubricator.

The Author, I think, would have got rather better results in his application of the displacement lubricator if he had fed the oil through a pipe passing into the steam branch leading to the cylinders, rather than apply it to the points on the valve head and piston head.

With regard to dampers on superheater engines, there is no doubt that these can be successfully dispensed with and complication aroided. There need be no fear at all in leaving the superheater flue tubes quite open and free, and the elements do not suffer.

I have scen trouble occur from pitting of elements on engines fitted with dampers; and I suppose it comes from the fact that, when the dampers are shut down, the elements. are enclosed inside a box with a certain amount of moisture and gas charged with sulphuric acid from the firebox, and pitting no doubt results.

Referring to the warming of the mechanical lubricator. I have know'n a case in which on a cold night the driver had forgotten to open the heating valve and discovered eventually that the lubricator had not been working properly, simply because the cold frosty atmosphere had so congealed the oil that the mechanical lubricator could not deliver it. The result was that the valies " seized" in the liners, actually tearing down the rocking shaft.

I am extremely obliged to the Author for bringing this. paper forward; it is highly practical and should produce a really good discussion.

Mr. J. Bliss (Messrs. C. C. Wakefield and Co.) : The Nuthor in his interesting paper states that the hydrostatic lubricator delivers oil proportionately to the time during which it is working and that consequently when working on an up grade the rate of feed from the hydrostatic lubricator is doubled owing to the shorter distance travelled in a 
given time, and it is particularly on this question that 1 wish to make a few remarks.

The mechanical lubricator feeds oil in proportion to the piston speed, that is, in proportion to the distance travelled and not to the time occupied, and the feed is in no way affected by the amount the regulator is opened and the consequent steam pressure; on the other hand, the feed at the point of application of the hydrostatic lubricator is entirely governed by the steam chest pressure.

To appreciate properly what takes place when using a hydrostatic lubricator it is necessary to follow the operations step by step and under varying conditions.

First, let us assume an engine ready to take out a train; the steam from the boiler is turned on and the feed is set to say four drops per minute. There is no resistance in the steam chest, consequently the steam will pass through the oil pipe at its maximum velocity and carry along with it the drops of oil as they leave the lubricator. Under these conditions the oil will probably reach the point of application at the same uniform rate as seen passing through the sight glass.

After starting, say with the regulator slightly opened, a resistance is set up in the steam chest, and the difference between the steam chest pressure and that in the lubrioator (which is, of course, always at boiler pressure) may be, say, 5o to 6olbs. This represents the margin of pressure available to carry forward the oil to the steam chest, but when the engine was standing, the pressure to carry the oil forward was equal to the boiler pressure, say, I $80 \mathrm{olbs}$. Consequently, the oil does not reach the point of application at the same rate as it did when the engine was at rest.

Now assuming the engine to be working heavily with regulator opened out, then the resistance in the steam chest is further increased and the difference in the steam chest pressure and that in the lubricator is only very small and may not exceed from 5 to rolbs. Under these conditions it is very doubtful whether any oil at all reaches the point of application.

Here we have a long length of $\frac{1}{2}$ in. diameter piping with a large volume of steam admitted at one end, and at the other end the pipe is throttled by a reducing piece for choke) having a $3 / 3^{2} \mathrm{in}$. hole. What happens is that the steam rapidly condenses and water accumulates at the lubricator side of the choke or baffle. The oil from the lubricator passes down the oil pipe and floats on the top of 
the water, the choke acting merely as a drain to carry away the excessive condensation. Owing to the pressure in the steam chest and that at the choke (which is fitted in or close to the stoam chest) being equal, the steam in the oil pipes is practically in a state of stagnation, therefore rapid condensation is bound to occur in these pipes. Immediately the regulator is eased or shut the oil and water which have accumulated in the oil pipe, between the lubricator and the cylinders, are blown through and a very large percentage of oil is wasted.

By admitting a large volume of steam in the oil pipe at the lubricator end and fitting a choke at the front end, to prevent a too rapid discharge, it is possible to maintain a fairly even pressure in the pipes, consequently the drops of oil may pass through the sight glasses with a fair amount of uniformity, but what locomotive engineers have chiefly to concern themselies about is the regularity with which the oil reaches the point of app'ication.

One of the leading railway companies in this country fitted a superheater locomotive having flat or D valves with a mechanical lubricator and an arrangement for admitting a jet of steam in with the oil, to carry it forward to the cylinders and act as an anti-carboniser, ${ }^{*}$ with the result that the engine ran perfectly satisfactorily, no carbonisation whatever being found, and the valie wear was actually less than in non-superheated engines of a similar class which are fitted with hvdrostatic lubricators. This would appear to support the contention that the oil from the hydrostatic lubricator does not reach the point of application when the engine is working heavily.

With the mechanical lubricator and anti-carboniser the state of affairs is quite different, and instead of the oil pipe becoming waterlogged, as described in the case of the hydrostatic lubricator, the mechanical lubricator will force the oil into the oil pipes against practically any pressure. The oil being discharged through the retention valve, where it is met by the steam jet from the anti-carboniser, is carrind forward through a short length of piping by the jet of steam direct to the point of application. There is not the slightest possibility of the short length of oil pipe, after leaving the anti-carboniser, becoming waterlogged as the steam is throttled at the anti-carboniser, and the steam and oil have a clear blow through after leaving the anti-carboniser. This is directly opposite to the case of the 
hydrostatic lubricators, in which the throttling is done at the far end, or close to the steam chest.

Even if the mechanical lubricators are used without an anti-carboniser, carbonisation will not take place providing the oil feed is cut down to moderate dimensions, say one pint per Ioo miles.

In cases where a good mechanical lubricator in conjunction with an anti-carboniser is employed, the oil feed has been reduced to 3 pint per 100 miles.

It is quite impossible to regulate the oil feed in a hydrostatic lubricator to anything like the degree of fineness that is possible with a mechanical lubricator. The latter when once set varies only with the engine speed, whereas in the hydrostatic lubricator the delivery of oil at the point of application undoubtedly varies with the steam chest pressure and the regulation of the feed is entirely in the hands of the driver.

Where one set of men will arrange the feed at say four to five drops per ininute, another set of men will not consider eight to ten drops too much, thus uniformity of feed is quite out of the question. In the hydrostatic lubricator time is the all-important factor, whereas in the mechanical lubricator time does not come into consideration at all. In other words, the amount of oil used in a sight feed lubricator is governed by the time occupied on the journey, that is to say, if an engine occupies two hours to run 100 miles a given quantity of oil will be used, but suppose the engine occupies four hours to complete the roo miles, then twice the quantity of oil will be fed, although only an equal amount of work has been done.

On the other hand, the mechanical lubricator automatically adjusts itself to the engine speed and the oil feed is governed by the mileage run and not by the time occupied in doing it.

The Author states that when the regulator is closed on approaching a station (the engine being fitted with a mechanical lubricator) the oil is exhausted from the feed pipe in front of the retention valves. It would seem from this that the action which takes place after the oil is forced past this check valve is not thoroughly understood. What really happens is that as the oil is forced past the check valve into the short length of pipe (which should be downwardly inclined), it is displaced by the action of the steam which enters the pipe from the steam chest directly the oif has passed the check valve. Consequently the pipe is never 
full of oil to be emptied as suggested and therefore there is no loss as the Author implies.

Mr. Smith Mannering, Member (L.B. and S.C. Railway): I wish to refer to the loss of oil which the las: speaker has mentioned, to which the Author attaches so much importance. The Author states that the oil is drawn away from the other side of the retention valves when the regulator is closed previous to a stop, and consequently the pipes (if any) have to be refilled again before the fore end receives Iubrication. In order to make this point clear, I have added a sketch (Fig. 4) showing the arrangement of the mechanical pump and its connections as fitted to some of our main line superheat express tank engines. It wili be seen that there are no pipes from the retention valves to the piston valves, but there is a very short length of pipe from the valves to the cylinders. I have also shown $a$ sketch (Fig. 5) of our latest type of spring retention valve. Any slight loss of oil is soon compensated for in restarting the engine, as the driving gear of the mechanical lubricator in the Brighton engine is attached to the engine valve spindles, so that the stroke of the pump gets the full benefit of the full gear of the engine in starting from rest.

The Author has a great objection to the use of the pump on account of the carbonisation of the piston valves and rings, and says that they have to be frequently taken out for examination and cleaning. We take out our piston valves for examination at periods of $5^{\circ}$ working days, and never between; they are invariably found to be in a good, clean and free condition.

One advantage of the mechanical lubricator over the hydrostatic type is the absence of long lengths of copper pipes from the anb to the fore end. I made inquiries this morning in our drawing office, and find that one of our main line non-superheat express tank engines fitted with $x$ hydrostatic lubricator with six feeds has no less than a total of 180 feet of copper pipe attached to it.

I can corroborate the statement made about the pitting of the superheater elements, as mentioned by the Author, but since we discarded the use of the smokebox dampers there is no trouble now in that respect.

As regards the proportion of oil delivered to the cylinders and valves, that is left very much to the discretion of the drivers. Some of the lubricators, notably the Wakefield, have special regulating devices for regulating the oil supplies to these parts, whilst in other types there are io such means for regulation. 
It may be gathered from the experiences that we have had on the Brighton Railway with the use of the mechanical lubricator fitted on the superheater class engines, covering now a period of over so years, that their continued use after this period is a sufficient guarantee of their usefulnes\$ and reliability under our own special service conditions.

Mr. R. P. C. Sanderson, Vice-President (The Baldwin Locomotive Works): There are a few points to which I should like to call attention in connection with this very valuable paper. As representing and being interested in the building of locomotives, I think it is inappropriate for me to say anything with regard to any special system of constructing lubricators. The locomotive builder should furnish anything that anybody wants; it is the right of the man who is buying the engine to say which lubricator he thinks best to use. But there are a few points which my own experience has shown me in the past to be very important in connection with the lubrication of cylinders, more especially in superheater engines. They are not mentioned in this paper, but they can very easily make success or entire failure of the particular lubricator which may have been applied to the engine, for which failure the lubricator itself is condemned and with which it had nothing to do.

The first is the location of the oil holes into the cylinders or steam chest. There is no need to have scieral hundred feet of pipe from a sight-feed lubricator in the cab to the cylinders. I can say with propriety, I think, that the general American practice on superheater and other engines is to run a single pipe on each side from the cab lubricator to iust above the steam chest. At this point usually there is a branch fitting, with two or generally three outlets in that fitting, which outlets are kept at the same level so that they all feed equally. One leads to the forward end of the steam chest, one to the back end, and the middle one to the cylinder barrel itself. The down pipe from the lubricator, sloping downwards to the steam chest, is either $\frac{1}{2}$ in. or $\frac{5}{8}$ in - on the bigger engines it is usually Fin. The branch pipes are smaller. The chokes are right at the outlets of the branch fitting or directly on the cylinder casting itself-the latter position being preferred by most engineers. Now if the holes leading the oil into the steam chest are not placed correctly a great deal of the oil will be absolutely wasted. The best position that I have myself found is one penetrating the valve bushing a little towards the admission edge of the valve, so that it can never be uncovered to the exhaust, but so that it is shut off inter- 
mittently by the travel of the valve-the effect desired being that which a Chinaman produces when he is moistening the linen when he goes to iron it, by spraying it out of his mouth. You want a kind of intermittent spurt to carry oil to the different points so as to ensure that it will be distributed intermittently. The same occurs from the choke on the barrel of the cylinder in the middle position near the top. That is, I believe, the practice most generally conceded to be right in America.

The character of the oil is vitally important. With steam temperatures ranging from $580^{\circ}$ to $670^{\circ}$, good results are not possible unless the fire test of the base mineral oil is at least $600^{\circ}$. Consumers should satisfy themselves of this by test.

Drifting indicator cards taken from a large engine show a vacuum ranging from 5 to glbs. on the exhaust side, this sucks ashes and soot down into the cylinders. Should the oil used be of a gummy or tarry nature, the ashes and soot will form with this a black crust or film. This will be found accumulated to a considerable thickness on the cylinder heads and in the passages. It will also be deposit ad in the bore of the cylinder and act as a fine grinding medium. To overcome this difficulty American practice requires either that the driver shan very slightly open the regulator when the engine is drifting or that a bye-pass value be provided which will automatically admit enough steam to the cylinders when the regulator is closed, to kill the vacuum and prevent the sucking in of ashes and soot.

That the chemical and physical structure of the cast iron used in the cylinders, valves, packing rings, etc., is of the greatest importance, has been shown by Professor Outerbridge in a paper presented to the Franklin Institute of Philadelphia. In this he demonstrated that the combined carbon in cast iron, when subjected to repeated reheatings at high temperatures was changed, resulting in a gradual swelling and softening of the nature of the iron which would seriously affect its wearing qualities.

The rule we have in America for running big superheat engines, where the cylinders range up to 30 and 32 in. diameter (some $36 \mathrm{in}$. recently), is that the driver must alway's open the regulator slightly when drifting, and as this is often forgotten, some designers provide by-pass valves so that when the engine is drifting a small amount of steam passes regularly into the cylinders from these by-pass valves over and above what reaches them through the displacement lubricator. 
Another important point that has not been mentioned is the nature of the cast iron. I do not know whether. you may have had any experience with the permanent growth of cast iron, due to repeated heatings over a certain temperature. Professor Outerbridge has explained the phenomenon with some very remarkable exhibits to prove it. It seems that the nature of the carbon in cast iron changes when cast iron is repeatedly subject to high temperatures. The casting swells and is softened. I was especially interested in this, because, many years ago, there was a steamer named the "Anthracite" sent over from England as an experimental ressel which I saw in New York. She carried exceedingly high pressure steam, which was subjected to a very high degree of expansion. It was an experimental engine. The engines were taken out after a short time and the boilers too, but on my visit there the chief engineer showed me a piece of a globe valve that had been good cast iron to start with, and you could cut that iron with a knife. It had become soft like rather hard lead. Professor Outerbridge showed that the changes occurring in the cast iron had this tendency. Now if cast iron be used with too great a percentage of carbon in it and of a character such that it can be most readily changed through repeated overheating, excessive wear will take place. The result of all this is that at present, I believe, the general practice in America is to use bushes made of special iron.: for the valve chambers and for the cylinders. For this purpose most people now are using an air furnace iron. It is melted in a reverbatory furnace and is made of selected materials. I think that in general about 12 per cent. of steel scrap is melted with the iron, making a higher proportion than usual of combined carbon in the cast iron; such iron is not affected by the high temperatures to the same extent as ordinary grey iron would be where the percentage of graphitic carbon is greater. It is therefore plain that the question of the character of the iron used is one of some importance, and, if not recognised, might have an effect in the matter of wear for which the lubrication would be blamed, but is in no wise responsible. In connection with this growth of cast iron and the change of nature of the iron itself, I may refer to some locomotives that were changed from saturated to superheated steam. They had the cylinders, ports, and passages designed according to the usual practice, contained within the body of the cylinder saddle itself. Very shortly after the change to superheat the walls of the cylinders begran to crack, and they all cracked along the direction of the incoming hot steam pa.;- 
sage. It was an illustration of what Professor Outerbridge had brought forward. The cast iron had grown permanently-not merely expanded from heat, but grown permanently where exposed to the high temperature of the steam, until it had become longer than the adjacent walls of the exhaust passages, and the consequence was it tore itsclf away. When the cylinders were redesigned so that these inside passages containing the superheated steam were separate and could expand without tearing the walls from the adjacent castings, all further fracture of the castings disappeared.

Mr. W. A. Lolean, Vice-President: The question of the lubrication of the cylinders of a locomotive seems to divide itself into two parts, viz., (I) the lubricator itself, and (2) its application to the conditions on a locomotive. If the lubricator is to be used in the cab so that the driver can see what it is doing, it naturally follows that a long length of delivery pipe is unavoidable, and therefore, in comparing the displacement lubricator with the mechanical, it appears necessary to compare them under the same conditions and with the same disadvantage of the long delivery pipe. Thus, it is not a true comparison to say that the mechanical lubricator at the front end of an engine does better work than a displacement lubricator in the cab, since were the displacement lubricator situated at the front end it would doubtless also give a more uniform delivery.

If this be admitted, it appears desirable in considering the whole question, to attempt to define what are the desiderata of a lubricator, and, if time will admit, then to consider the further important point of how best to appiy such lubricator to give the best lubrication of the cylinders.

Starting then with the lubricator, the points which appear most important in determining the relative value of a lubricator are :-

(I) That the lubricator shall deliver with certainty a pre-determined amount of oil corresponding with the setting of its adjustment.

(2) That such oil shall reach the point of delivery regularly.

The subordinate points of facility for filling, flushing, changing of glass, cleaning out, adjustment, oil beight gauge, lasting qualities of mechanism, which are all of importance, are quite subordinate to (1) and (2).

The argument seems to be that, whilst admitting that a highly ooncentrated piece of mechanism may make a 
more exact and accurate delivery possible, the upholders af the displacement lubricator ask if their simpler type, with its avoidance of so many working parts, will not do its work sufficiently well for its purpose, and therefore compare forourably with the mechanical lubricator with its chances of mechanical breakdown. Considering the matter broadly, as the long delivery pipe is inseparable from the displacement sight-feed lubricator, we must include this pipe as an integral part of the lubricator system, and there appears no doubt that this long pipe does interfere with the oil (which may pass the sight-feed glass regularly enough) being actually delivered with the same regularity at the cylinders.

Comparing, therefore, the relative merits of the two types of lubricators, it seems imperative to have accurate data from actual experience under running conditions, and if any members can give information on these points it will be most valuable.

Even on such vital questions as the following, one finds great differences of opinions through lack of actual data.

(I) Is the same amount of lubrication required in the cylinders of an engine using saturated steam, $(a)$ when the steam is on, and $(b)$ when the regulator is shut?

(2) Does the amount of lubrication required in the cylinders increase $(a)$ with the piston speed, $(b)$ with the mean effective pressure in the cylinder?

(3) When questions (1) and (2) are answered, do the same answers apply to an engine using superheated steam?

Were reliable answers forthcoming to the above questions it would assist in a more accurate judgment of the relative value of displacement and mechanical lubricators.

Disregarding exact niceties, it appears that, with saturated steam, if the oil feed be set for the normal running condition and a choke plug be used on the lines of that fitted with the Detroit lubricator, the feed from an ordinary displacement lubricator will be found quite satisfactory and no great harm will occur under any conditions. If so, the avoidance of upkeep troubles may, and probably will, more than compensate for the slighti: higher consumption as compared with the mechanical lubricator.

Turning to the case of superheated steam, however, it seems essential that there shall be no serious intermission or irregularity in the feed, and that, if a reasonable amount of care be taken in the upkeep, the mechanioal lubricator 
makes it possible to deliver the minimum quantity of oil required with a certainty and regularity impossible with the displacement lubricator.

Turning, however, to the application of the two systens, the displacement type by employing a steam jet to carry the oil forward from the lubricator obtains very great assistance in the employment of its oil to the best advantage for effecting its purpose.

All told, therefore, it seems in the case of superheated steam, for which continuity of the lubrication is essential, that a mechanical lubricator with a positive feed combined with a steam jet to atomise the oil after it leaves the nonreturn valve and to distribute it uniformly all over the surfaces requiring lubrication is a good arrangement.

With regard to the lubricators on the intensifier principle, such as the Intensifore, this type was tried many years ago; amongst others Messrs. Dewrance, I believe, made a lubricator working on this principle at least 20 years ago. These offer a reduced number of working parts to get out of order, and provided the hat-shaped leather washers on the plungers, on which the whole efficiency of the lubricator depends, are found to keep perfectly tight after being in service for a time, they should prove very acceptable and almost as simple in upkeep as the ordinary displacement type. It would appear, however, if the disadvantages are to be avoided (under which the displacement lubricator also labours) owing to variation in pressure in the steam chest as compared with that in the lubricator, that as large a difference in the rams as is reasonably possible should be allowed, otherwise its delivery will compare unfavourably with the almost irresistible pressure in the delivery from the ordinary mechanical types. On the other hand, with this intensified pressure there may be trouble in getting a steady drop by drop delivery.

Turning to the question of the application of any type of lubricator to cylinder lubrication, the two main points to be decided (and they can only be considered in conjunction) are $(a)$ in what form should the oil be delivered to reach all surfaces in the cylinders requiring lubrication, and $(b)$ at which points shall the delivery of the oil be made. Looking at the first point, it appears a safe method to impregnate the incoming steam with oil and allow the steam to distribute it automatically everywhere. Though a considerable quantity of the oil may in this way pass right through the cylinders with the steam without depositing on the surfaces, yet it seems a surer way of reaching every point to be lubri- 
cated than to inject oil at two or three points in the steam chest or cylinders and trust to its being distributed thence over the rest of the surface. Recognising that it is absolutely necessary to lubricate every part of the rubbing surfaces, if sufficient oil is to be introduced by either method to ensure reaching the furthest point to be lubricated, it seems that it will probably be necessary to introduce as much oil in excess of the minimum required when it is introduced at two or three points as would be necessary if the oil were introduced in an atomised form into the steam pipe before reaching the cylinders, and the latter therefore secms the safer method.

The question as to who shall adjust the feed must be a matter for individual railway running administrations to decide, but there seems a growing feeling amongst locomotive officers that the drivers should be able to see what is happening, and that it is not quite satisfactory to have the lubricator at the cylinder end, thereby removing every sort of responsibility from the driver for lubrication troubles. If it be contended that the setting should be done by an expert in the running shed and that the drivers should not be allowed to tamper with the feeds, then by all means arrange a lubricator with its adjustments inside a lid which can be locked, but let the driver have sight-feed glasses and access to the values (if they are liable to stick) and to the flushing arrangement and by-passes (if any). Such by-pass arrangement, although an extra complication, seems a desirable addition, in that it allows a driver, by turning it on in case of a broken sight-feed glass, to get to the end of his journey without renewing the glass.

Returning to the ideal to be aimed at in lubrication, Mr. Clayton emphasises the desirability of having steam to atomise and to carry the oil into the cylinders, but if the oil is introduced into the steam pipe through an atomising delivery nozzle it will possibly be found unnecessary to use an extra steam jet to atomise the oil except when the regulator is shut. In this case the arrangement in use on the Burma Railway, as shown in.Figs. 6 and 7 , seems to be an economical way of automatically working such atomising jet whenever the regulator is shut. In this design advantage is taken of each opening of the antivacuum valve to trip open'a small steam valve. Efficient anti-vacuum valves seem essential if fouling of the passages is to be avoided through ashes being sucked down the blast pipe each time the regulator is closed, and adhering to the superfluous oil coating the inside of the blast pipe. 
We have to thank Mr. Bliss for his contribution as giving a very clear and lucid statement of the objections to the displacement lubricator.

The delivery valve which Mr. Mannering has kindly brought with him is interesting as showing what has actually been tried for preventing the oil pipes from being emptied each time the regulator is shut. If others would also bring forward little details of this sort which they come across in practice much useful information would be derived.

Mr. Sanderson referred to a lubricating system in which one oil delivery terminated in two or more branch delivery pipes. Such branch deliveries were tried for some cylinders in which the valves were lubricated by passages delivering up into the bridges of the cylinder value faces and were found a failure because one or other of these passages always carbonised up. In spite, therefore, of Mr. Mannering's natural objection to the yards and yards of copper piping, if so much is necessary to have feeds to three points in each cylinder-which does not seem settled-then it seems imperative to have six separate delivery pipes.

Mr. T. C. Thomsen, Nember (The Vacuum Oil Co., Ltd.): The Author mentions the oil consumption on his locomotives, and gives a figure of about two pints per hundred miles, which is practically double what it probably ought to be. I do not think he would have anything to fear from cutting down his consumption to one pint per hundred miles if he used a good-quality oil. It is a fact that with impurities getting into the engine, the more oil you feed, the more deposit you get, so that excessive oil consumption is no cure for deposits; it is rather the reverse.

Then there is the question of the nature of the carbon deposit. It may interest the members to know that, in stationary practice, I know of several cases where large engines using highly superheated steam are fed with oil direct into the cylinders, not atomised, and over long periods there has been no carbonisation whatever, owing, I think, to the purity of the steam. With absolutely pure steam and reasonably good quality oil there is no carbonisation; that is the experience in stationary practice which might be very closely watched.

When the steam contains impurities, the way the oil is applied is of the greatest importance. In stationary practice, atomisation of the oil has given very good results. About twelve years ago $I$ designed an atomiser for stationary engines, this is indicated in Fig. 9. There 
is no patent about it so that anyone can use it, and there are now many thousands in regular use, and they have been of great benefit in minimising deposit and reducing oil consumption.

Coming to locomotives, I am quite sure that the matter drawn in from the exhaust is at the very root of the formation of deposit, and, although on a reduced consumption, say one pint per hundred miles, applied with a mechanical lubricator, there would possibly be only very little deposit ; yet I do not think we can quite prevent the formation of deposits with mechanical lubricators unless the oil is distributed by means of a jet of saturated steam. It will appear from the remarks of Mr. Clayton and others, and also from Mr. Sanderson's remarks, that with large superheater engines there is always a tendency to have a little breath of steam coming in, and no doubt this helps to prevent the impurities from caking inside the engine und baking together with the oil.

The Author complains about the alteration in the rate of feeds due to the lubricator being exposed to cold, and he also mentions that, with a very hot oil, the feed will increase. My experience is that, if you have a good mechanical lubricator and the speed of the plungers is not above 20 strokes per minute, then as long as the oil will flow into the pump on the suction stroke and fill the space entirely the feed will not vary appreciably whether the oil is boiling or is just moderate in temperature. So long as the oil will flow into the pump the feed should be practically constant at all temperatures, but of course it is necessary where the lubricator is exposed to cold to have a heating pipe to make sure that, even at the lowest temperatures, the oil is always sufficiently fluid.

With regard to the Detroit lubricator, on the $L$. and S.W. Railway, there are, I think, 32 of these on their superheater locomotives, and they have all given satisfaction. The first lubricators fitted were six-feed Detroits, three feeds on either side, one to the cylinder and one to either end of the piston valve. After that it was found unnecessary to have three inlets, and subsequent lubricators have only four feeds, two feeds to either side, one to the cylinder and one for each piston valve. There has been no trouble with carbonisation since they were fitted.

Mr. Bliss remarked on the irregularity of feed of the Detroit lubricator. It is impossible to know what takes place inside the pipes Jeading from the Detroit lubricator to the engine, but we know it to be a fact that the oil does 
get to the engine and is satisfactorily distributed. Experience has proved with Detroit lubricators, even with superheated steam, that the engine valves and cylinders are well lubricated on a reasonable amount of oil. I think it is very likely that, with a good type of mechanical lubricator coupled with a good type of atomiser or atomiser box, the consumption of oil can be reduced compared with the consumption needed with a displacement lubricator. The mechanical lubricator takes the oil consumption very much out of the driver's hands; if you take those feeds which are intended to serve the engine, lead them to an atomiser box, and properly atomise the oil in the same way as it is done in stationary engines, then undoubtedly you will get good distribution of the oil on a minimum consumption.

The question of reliability in service is a feature that may well be open to discussion. It is a fact that on the Continent mechanical lubricators are very largely fitted to superheater engines, also in the East and in South America; on the other hand, the United States use Detroit lubricators almost exclusively.

Referring to Mr. Lelean's remarks and the query whether the oil consumption is greater if the steam is on or if the steam is off, I think this is very largely a question of the type of valves. I forget who told me, but I think it was somebody from Canada, who used slide valves in connection with highly superheated steam, and his experience was that when " drifting" they actually required more oil than when on full steam. With the slide valves, the diffculty of getting the oil introduced was so great that, during periods of "drifting," the oil could not get in unless there was a good surplus feed to the valves. With piston valves it would be different, as they are easier to lubricate than slide valves.

On the whole, I think the oil feed should rather be according to the area of cylinder surface swept by the piston. This is the experience from stationary practice and $I$ think that it would also apply to locomotive practice. Whether the mean effective pressure is high or low, as long as it is not a question of the extreme difference such as between full load and "drifting," I think the oil consumption should be independent of moderate variations in the mean effective pressure.

With regard to the intensifier, I have had no actual experience with it, but I understand that pressure exerted on the oil forces it through different sight-feeds, the oil feed being controlled by means of adjustable needle valves. As 
the ram is fitted with leather washers which create friction, a considerable surplus of pressure is needed to make sure that the oil is forced through the sight-feed glasses, and consequently the regulation must be extremely fine. For this reason they are easily choked with dirt and will easily get out of order. The same principle has been employed in several lubricators used for stationary engines and the objections to their use are the same as just mentioned. Furthermore, the feed will depend absolutely on the viscosity of the oil. If the oil is cold, the oil will feed slowly; if the oil is warm, it will feed quickly; and any temperature change will affect the riscosity and therefore the feed of the oil. The oil feed varies not only with the viscosity of the oil, but also with the back pressure. On one side of the control needle valves you have the pressure to which the oil is subjected, and on the other side you have the cylinder or value chest pressure. Obviously, the feed will vary with the back pressure, and for the above reasons the intensifier lubricator cannot be made to deliver so uniformly as the mechanical lubricator.

There is one point which has not been touched upon by any of the speakers. It is the question of oil for the axleboxes. With a mechanically operated lubricator there is automatic control of the supply of oil to the axleboxes. and the mechanically operated lubricator can be arranged with two compartments feeding cylinder oil to the steam cylinders and valves and axle oil to the axleboxes.

Perhaps I may claim to have originated the idea of the combination of mechanical lubricators with atomisation of the oil, as mentioned in my paper read before the Institution on March $25^{\text {th }}$, 19I5. Very little experience has been gained during the war, but subsequently I hope this question of mechanical lubricators and atomisers will be satisfactorily solved. Fig. 8 shows a design for the installation of an atomiser in connection with a mechanical lubricator, the details of the atomiser being shown in Fig. 9.

I would like to say that this paper forms a most interesting contribution, and I am quite sure the discussion that we have had to-day is one of the most useful we have had for some time.

Mr. Dunn, Graduate (L. and N.W. Railway): In connection with the question of carbonisation, our experience on the North-Western is in agreement with that of the Author, in that the deposit is not formed to any extent while running under steam, but only when drifting, and it is interesting to note that an analysis of the deposit has shown it to 
consist of finely divided material which is drawn down the blast pipe into the valve chest when the engine is " drifting." Experiments have proved that a vacuum of from 5 in. to $15 \mathrm{in}$. of water is obtained when running with the regulator closed and the reversing wheel in the running position, that is, three or four turns back, but when in full gear no vacuum is formed. The drivers have therefore been instructed to put their engines in full gear immediately the regulator is closed.

The allowance of oil on the North-Western is one pint for every forty miles, and is the same for either superheater or non-superheater engines of the same class.

Sight-feed lubrioators are not employed on any of our superheater engines, mechanical lubricators being in sole use. Those types in use indude the Wakefield, Trusty and Bosch, the former being in the majority.

With reference to the lubrication of axleboxes, we have experienced considerable trouble with the left driving axleboxes of certain eight-wheel coupled engines, and on, I think, four engines, we have tried the Wakefield lubricator for the whole eight boxes. We find they can run from london to Rugby and back, ifo miles, with one and a half pints of oil and give no trouble whatever; but almost every other non-fitted engine of that class continues to give trouble.

Mr. Thomsen asked for particulars of the oil grooves.

Mr. Dunn: There is a channel about $\frac{1}{2}$ in. wide and $\frac{1}{2}$ in. deep right across the crown of the box parallel to the axle and they usually do not have any other oil groove at all.

Mr. Thomsen: Does the lubricator use the oil at great pressure?

Mr. Dunn: I do not know; just the usual amount. It is the same type of lubricator as is used for lubricating the cylinders.

Mr. Thomsen: What is the result of using the flexible metallic tubing?

Mr. Bliss : As a matter of fact, what we are using now is armoured rubber hose, special oil resisting. We tried flexible metallic tube and had a lot of trouble with breaking of joints, but with the present armoured hose we have very little trouble indeed. I have a piece in my possession now which has been subjected to test on running for 22 months and is practically as good as new. The theory is, I believe, 
that no air is admitted to the inside of the tube, and consequently oxidisation does not take place.

Mr. Thomsen : 1 think it would be very interesting to find out when applying mechanical lubricators to axleboxes whether it is absolutely necessary to have the oil used under pressure. I think, with a great many bearings, if the oil is simply introduced into the bearing, that it will find its way round and distribute itself, and that it is only in very exceptional cases, as in the case we have just heard about, where probably the edges of the oil grooves have worn sharp, that it becomes necessary to lift the brass off the journal in order to get the oil film formed. In many kinds of stationary practice with forced-feed circulation, it has never been found of great advantage to introduce the oil under pressure as long as the oil reaches the bearings in sufficient quantity.

Mr. Bliss: We find it very much better to have the oil under pressure for the simple reason that under all conditions you get very much lower friction if you have the oil forced in and tending, so to speak, to lift the box from the journal.

Mr. Lelean: There is a growing tendency amongst engineers to ask for axlebox lubrication from a mechanical lubricator, and this point as to whether it is an advantage to have the oil forced in under pressure is an interesting one. Probably under normal circumstances no great advantage will result from pressure feed to ordinary coupled axleboxes, but, on the other hand, in case of a hot box, by giving full feed to that box the driver should always get through without a stop.

Mr. Bliss : I think the point is this. The majority of locomotive axleboxes are fitted with a fairly deep oil groove along the centre line of the box, and it is preferable that the oil in the groove should be under pressure at each stroke of the lubricator pump in order to force it between the rubbing surfaces. Further, should any obstruction occur in the oil passayes, due to dirt or the metal dragging over the oil hole in the brass, the oil being under pressure will force a passage and so prevent the box running hot.

Mr. Lelean: I think any members who are thinking of introducing axlebox lubrication from mechanical lubricators may be interested in the opinion of one of the locomotive superintendents in India, that "if the lubrication of axleboxes is to be a success, the first thing to tackle is the hose pipe, for. from the condition in which he received the hose 
pipes and their couplings in India, he concluded that they would give trouble from the very start."

Mr. Thomsen : Mr. Sanderson said we must use an oil of sufficiently high flash point and point of evaporation. That may convey the impression that as long as the flash point and point of evaporation are high enough, everything will be well. I would like to oaution engineers against using oils with too high a flash point and too high a point of evaporation, because some oils of that character are exceedingly viscous, and the more viscous cylinder oil is the more easilv will the impurities, when they are drawn into the cylinder, cling to and bake together with the oil, thus forming deposit not only in the blast pipe but in all the exhaust and steam passages. It is an experience I have had repeatedly that, with highly superheated steam, it is desirable to use a cylinder oil which is not too heavy in viscosity. On the other hand, the oil must be sufficiently viscous and have a sufficiently high flash point to give sufficient lubrication at the temperatures prevailing, but that is really not in the first instance a question of flash point, but a question of the crude oil from which the cylinder oil is made and the wav it has been refined. To illustrate this feature in another way; take the question of air compressors. I remember some years ago there were a number of explosions in South Africa; there was a committee instituted to inquire into the cause of the explosions, and they laid down the rule that no oil should be used with a flash point less than $520^{\circ} \mathrm{F}$. for air compressor lubrication. The result was, I believe, that there were more explosions than ever, because the oil was too viscous. The impurities in the intake air baked together with the heavy oil and caused the outlet valves to stick, and the wire-drawing of the air through the valves caused excessive heat and occasionally explosions. Therefore, as a general rule, cylinder oil should be used as light in body and as light in viscosity as possible to do the work with sufficient margin of safety.

Referring to the springless valve which Mr. Mannering exhibited, I have always held the opinion that a check valie, to be a real check valve, should have a spring and should be closed against the delivery from the oil pump. In all the lubricators I have had to do with that has always been the practice, and I fail to see the advantage of a check valve if it does not close properly on its seating. Particularly in locomotive practice I think the tendency will be for the steam to pass through the little grooves in the face of the check valve shown and thence find its way to the highest 
point in the delivery pipe, so displacing the oil and causing it to flow down into the cylinder and thus empty the whole delivery pipe in time. I may be wrong in my conclusions, but I cannot see better than that a check valve should be held on its seat by a spring and should be pushed open by means of pressure from the pump forcing the oil through the valve.

Mr. Mannering : The pump will relieve itself by forcing the valve up against the spring, or without the spring it will find its way through these little relief passages cut through the seating.

The President: I think we had better examine this valve in detail afterwards.

Mr. J. Rodgers : Could Mr. Thomsen give us an idea of the flash point of the oil which is generally used for air compressors?

Mr. Thomsen: The flash point for air compressors generally should not exceed from 400 to $440^{\circ} \mathrm{F}$. unless you have very special conditions. You would be ill-advised in using oils with higher flash point.

('The President having to leave, Mr. W. A. Lelean, Vice-President, took the chair.)

The Chairman: I will ask the Secretary to read a contribution from Mr. Geer, who was to have been here to-day but was unexpectedly called away this morning.

Mr. Geer, Member (The Superheater Corporation, Ltd.): The Author's paper offers opportunities for discussion on varied subjects, but I propose to confine my remarks to the lubrication of valve chests and cylinders.

I hardly think that he is correct in stating that one of our leading English railways uses a displacement lubricator in connection with highly superheated steam. The railway in question, the Great Western, does not use what is now considered a high superheat and therefore is not working under the same conditions as other railways where high steam temperatures are in use.

There is, of course, no physical reason why oil fed by liquid displacement and gravity should not equally well lubricate a cylinder working with dry steam as with wet, but what is claimed by the advocates of the forced-feed system is that oil fed from a liquid displacement lubricator when delivered by a long pipe to the steam chest and cylinders is very far from being the same at the point of delivery as it appears to be in the sight-glass. 
It may be contended that the presence of the steam jet in the delivery pipe ensures the latter being scoured clean of oil at atl times, each drop delivered by the lubricator to the delivery pipe being at once atomised by the jet and carried to its work.

So far as the cylinder feed is concerned this may possibly occur since the mean cylinder pressure (not the mean effective pressure) is very much lower than that at which steam is delivered to the jet. With the steam chest it is otherwise, for this may be anything from boiler pressure to 7 or 8lbs. per square inch below that of the atmosphere.

When the regulator is fully opened (or even only partly opened when the piston speed is low), the steam chest pressure will vary but little from the boiler pressure and there will be no difference between the steam chest pressure and that of the steam jet to induce velocity of flow. The oil, therefore, will have a tendency to accumulate in the supply passage at the time when the engine is doing its heaviest work and when it needs it most. When steam is shut off and the steam chest pressure falls, the steam jet comes on with full force and rapidly carries all the oil forward to the steam chest at the time when it is not wanted.

On re-admitting steam to the steam chest the pressure against the steam jet is increased and its velocity is reduced or destroyed altogether, so that before any oil can reach the steam chest, sufficient must have been delivered by the lubricator to coat completely the lower part of the delivery pipe, and by the time this has been effected several minutes will have elapsed. Oil will not flow drop by drop down a dry surface as mercury does, each drop adheres to the metal and gradually becomes smaller as it travels until it disappears as a stationary film on the metal. The next drop travels further, and so on, until finally the whole path to be traversed is covered with an oil film, after which regular drop by drop delivery proceeds.

When a mechanical lubricator is used it is customary to provide a check valve loaded to some pre-determined pressure well in excess of any possible steam chest vacuum so as to have the pipe fully charged at all times. The check valve should be placed absolutely on the steam chest or cylinder, or if this is impossible it should be placed below the inlet, so that it will not be possible for oil to gravitate from the portion of the delivery pipe between the steam chest and the check valve. These points are of great importance and serious trouble has been caused by being overlooked. With check valves properly located oil cannot be 
sucked out, there is no elastic fluid pressure to force it, and therefore, even when steam is shut off and a considerable vacuum exists in the steam chest and cylinders, the delivery pipe remains fully charged throughout its length and continues to deliver the oil at the regular drop by drop rate determined by the pump displacement.

The Author may be right in assuming that sudden flooding of the steam chests from the feed pipes in front of the check valves occurs when steam is shut off, provided these pipes are sufficiently large to enable both the descending oil and the air that must ascend to replace it to pass each other in the same pipe, and also that the check valves are placed high enough above the steam chest oil inlet to give the oil head enough to start the action, but with the small pipes generally used it is most unlikely to occur. It is doubtful, however, if a pipe large enough to permit steam or air to enter to fill the vacuum caused by the departing oil would permit any oil at all to collect to cause flooding, as if air could enter when steam is shut off there is nothing to prevent steam doing so when the regulator is open. In cases, however, where long passages are provided in the cylinder castings to conduct the oil from the check valves to the piston valve heads, and these passages are not of very small bore like the lubricator delivery pipes, intermittent and unsatisfactory oil delivery would occur.

The Author's case against the ordinary pump type of mechanical lubricator seems to be condemnatory enough without imputing a fault which, if properly fitted, it does not possess, but which is considered one of the chief objections of the hudrostatic displacement lubricator, viz., that the latter depends upon a steam jet (whose power decreases or may even vanish altogether when the regulator is open and when its services are most needed) to do the work of rapidly bringing a drop of oil down a pipe along which the oil cannot come by gravity for a long time after the lubricator is put in operation.

Engineers want to feel confident that when steam is turned on the oil will be where it is required and many therefore prefer to rely upon a pump or press for the purpose. Certainly both these appliances, as usually arranged, are open to objections; the Author has enumerated a number of them.

The mechanical lubricator is a conscientious but unintelligent worker; it goes on laboriously delivering so much oil per revolution without the slightest regard to the real needs of the steam chest and cylinders, ovar-feeding them 
at times, starving them at others. The results of the former process of over-feeding are commonly abundantly evident in the carbonaceous deposits, but have been endured on account of the still worse consequences that would follow a defiency of oil at a combination of a slow speed and high power.

Undoubtedly it is desirab'e to be able to regulate the feed intelligently to suit the requirements, and for this a sight-feed of some sort is necessary, but a sight-feed that does not indicate what is happening at the steam chest end of the pipe at all is apt to give a false sense of security. A hydrostatic sight-feed lubricator placed directly on the steam chest or steam pipe of a marine or stationary engine does give a true tale at all times, but it is very much otherwise on a locomotive where the "lag" of a long pipe has to be taken into account. If it were possible to have the steam jet at a pressure well above that of the boiler so as always to ensure a high velocity of steam in the oil pipe, the objection would vanish, but this is not the case in any such lubricator on the market, and it would entail complications in the way of a special steam generator, feed pump, and so on, that would soon put it out of court.

Apart from this course, the only way to make a displacement lubricator work with a full bore pipe so as to be ready to deliver oil to the steam chest immediately it is started, is to deliver the oil through a loaded check valve. This entails the displacement chamber of the lubricator being at a higher pressure than any possible steam chest pressure that can possibly occur. This is impossib'e if the hydrostatic displacement be used in the usual way.

There is, however, a new type of displacement sightfeed lubricator in which the oif is supplied through the sight-feed glasses at a pressure some $5^{\circ}$ per cent. greater than in the boiler, being maintained at that pressure and displaced by a ram or plunger working in a large oil cylinder and driven down by water at boiler pressure acting on a piston on the end of a ram. The lubricator in question is known as the "Intensifore," and is fitted to a large and increasing number of modern locomotives using highly superheated steam.

There are no moving parts connected mechanica'ly to the motion of the engine, and the whole arrangement is located on the footplate under the eye of the engineman. Any number of separate sight-feeds can be arranged, and any or all of them can be shut off or regulated independently without requiring any attention to the power supplied. The 
delivery is practically constant at all steam chest pressures, so that when the required rate of delivery is once set in the glass no further attention is needed. It is claimed for it that it combines the good points of the mechanical and hydrostatic displacement lubricators and is at the same time free from the faults of both.

Mr. G. F. Burtt, Member (L.B. and S.C. Railway) : On the Great Western Railway the oil is atomised and distributed by a special steam pipe controlled by the regulator. The engines work at the high pressure of $225 \mathrm{lbs}$. per square inch and with an average superheat of $140^{\circ}$ Fahr. Through the courtesy of Mr. S. J. Churchward I am elkabled to describe and illustrate the arrangement. (See Appendix II.)

The Chairman : Some of the most valuable remarks are at the end of the paper and are a welcome contribution from one with practical experience on the question of superheat. The Author advocates notching up and working with a full regulator on the ground that this method ensures the steam remaining a certain time in contact with the walls of the elements and enables it better to pick up superheat. It seems, however, that though this appears a natural conclusion, it is really fallacious. Fxperience with superheaters seems to show that to pick up the superheat from the surface of the tubes requires that there shall be a distinct velocity in the steam so that it will impinge on the sides of the tubes, and if the steam coming through the superheater elements moves too slowly, instead of accumulating the heat (as anyone might naturally expect without actual experimenting), as much heat is not obtained. It is on the correct designing and proportioning of the elements to get the correct velocity for obtaining the required superheat that the success of a superheating installation largely depends. Therefore, it seems that it is not good practice with an engine using a superheater as normally designed to work with the lever highly notched up and with a full regulator. This is perhaps worth putting on record as the experience of the superheater people themselves.

I feel, gentlemen, although we have a comparatively small attendance here this afternoon, that many of the remarks have been very valuable, and I am sure this Institution is growing by the appreciation that is being felt by the engineering world of the contributions which are made in this room from time to time. Although, owing to the war, attendances are not large, yet the Institution is going ahead by leaps and bounds, as is instanced by the high 
rank of the members who have lately joined our Institution. I think the Secretary is to be congratukated on the number of members who have joined our Institution during the last few months.

The Secretary points out that if every member will do what he can to bring the Institution to the notice of other bocomotive engineers that we shall certainly increase and go ahead very rapidly now.

On the motion of the Chairman a rote of thanks to the Author for his interesting paper was put to the meeting and carried unanimously.

\section{CORRESPONDENCE.}

The President, in continuation of his remarks, wrote that he regretted he had been unable to remain until the conclusion of the meeting; the paper had resulted in a most interesting discussion on a subject which affected the success of superheating so intimately. The respective merits of the mechanical and hydrostatic lubricators had been well brought out.

In America he understood the hydrostatic or sight-feed lubricator was universally adopted for superheater engines, but probably one of the chief reasons for its successful working was the fact of the drivers being trained more as engineers than in this country. While there was no doubt that this type of lubricator gave good results on some of the English railways, he considered the mechanical lubricator was likely to become the more successful of the two now that the steam jet had been added. The addition seemed to get over the chief objection to its use by reducing the carbonisation in the steam chest.

As regards the consumption of oil, that could be kept within defined limits with a mechanical lubricator better than with a hydrostatic type in which the flow of oil required frequent regulation by the driver.

Oil is usually issued to an enyine according to the mileage it had to perform, and the lubricant is carried to the front and back piston valve heads and to the centre of the cylinder.

The Author need not anticipate any trouble from the absence of dampers. 

follows :-

The Author replied to the discussion in writing as

I must first correct a slight misunderstanding on the part of Mr. Clayton, who is apparently under the impression that the point of application of the lubricant is at the valve heads, whereas I stated that there is one single point of applioation at the top of the steam chest and midway between the valve heads with the valve in central position. As to application in the steam branch this does not allow of the necessary fall to the oil supply pipes such as is advocated so strongly and rightly by the makers of the displacement lubricator.

From the experience of several membe:s, it cannot be doubted that the anti-carboniser is a most useful adjunct to the mechanical lubricator, but I much regret that $\mathrm{Mr}$. Bliss did not enlighten us as to the effect of this apparatus when standingr. There was a demand in America some time ago for a so-called "drifting "valve, i.c., some automatic device which should supply steam in small quantities to the fore end when running with regulator shut, but a necessary requisite was that it should close automatically when the engine came to rest. To the best of my knowledge no such device was put forward, and any other which did not fulfil these conditions was deemed dangerous, so that drivers were advised to "crack the throttle" on long down grades, a practice evidently adopted by the driver to whom Mr. Clayton refers, whose engine remained so free from carbonisation. I lay great stress on this as the human element must always be taken into account, and steam is in this case injected into the fore end without oil. Mr. Clayton's remarks on this point deserve the attention of Mr. Bliss. In 1913 the Author fitted an experimental valve to one of the superheater engines on the Western Railway of Buenos Aires, worked from the regulator as in the case of the G.W.R. lubricator steam valie, for admitting steam through a in. pipe to the saturated side of the header when the regulator was shut. Although the superheater side of the header was provided with an automatic exhaust valve, the engine on two occasions started off by itself and our people removed the apparatus. Unfortunately, a few days before this engine was put on the road I had to go up country, and it was 12 months later before I had any opportunity to carry out experiments personally. Sir Vincent Raven, of the N.E.R., has, I believe, since made a success of a similar idea, and I await with interest the sketch of the trip valve in use on the Burma Railway, referred to by Mr. Lelean. I may say that the object of the valve in 
my case was chiefly to avoid overheating of the elements and undue reduction in temperature of valves and cylinders, at the same time to act as an atomiser, and it was fitted at a time when dampers or draught retarding valves were looked upon as necessary component parts of the superheater. We had not yet ventured to abolish dampers, etc., altogether. I hoped to avoid condensation in the cylinders as the steam was to a certain extent superheated and in circulation before reaching them. There was a by-pass valve to put the whole scheme out of action during such time as the engine was in the running shed. I merely mention this as an example of the danger caused by steam blowing uncontrolled into the fore end, although as to quantity, I fully understand that it is more or less the same as with sight-feed and anti-oarboniser. There still remains this difference that in the former we have steam and oil, and in the latter steam alone, which must produce the effect noted by Mr. Clayton.

The argument adduced against the hydrostatic lubricator by Messrs. Bliss, Geer, and others, that when the engine is working its hardest it is doubtful if it receives any oil at all, is one generally brought up against this system by its opponents, but I think there is a lot to be said in practice against such a statement. The oil is also under the pressure of the column of water in the condenser in the case of the "Detroit," and while admitting that what takes place exactly between lubricator and valve chest is to a certain degree a matter of conjecture, the fact that a sufficient amount of oil reaches its destination regularly (as admitted by Mr. Thomsen) seems to be proved:-

(a) By the adoption of this apparatus in the U.S.A. with their high steam pressures and enormous cylinders. The North American people do not spare their engines when on the road, and deficiency of lubrication under such conditions would wreck the fore ends in no time, and however much the driver were trained as an engineer he could not overcome a manifest mechanical or natural failing in the principle of his lubricator.

(b) To come nearer home, Mr. Clayton reminds us that the L.S.W.R. uses "Detroits," and I now know this to be the case on the conversions to the Eastleigh superheater, and on new locomotives designed and built by Mr. Urie. This railway has a road all "against the collar" for something like the first hour out from Waterloo, and on a heavy train I seem to remember that the engines used to get their full share of being " slogged." Under present 
conditions, even allowing for increased power of the locomotives, they must still get their share of rough work over this run. With regard to the contention put forward that the engines get practically no oil during the whole of this period, I have beard the valves of a superheater engine groaninix within a very short time after the failure of the lubricator, and 1 have seen the scoring caused by such failure and deficient lubrication, so that I consider the best answer on this proint is that if the L.S.W.R. are able to keep their engines continually on the road using hydrostatic lubricators, then the valves, etc., are receiving proper lubrication.

(c) Consider the effect of the condensation of steam and accumulation of witer on the lubricator side of the choke. were such present. As the steam is thus in a state of stagnation in the supply pipes, once condensation is started at the point mentioned, these will rapidly fill with water; and the oil, beink still fed past the sight-feeds, floats on the water which is now immediately above the sight-feed glass, at which point the oil will all accumulate; this would obstruct even feed past the glass. I do not think the uil would feed regukarly past the needle valve unless it were passing with almost the same regularity to the points of application.

In so far as stationary practine is concerned, it may be to a reasonable extent true that carbonisation will not take place under moderate oil feed, but in locomutive practice I differ from this upinion. If any road at home has the oil consumption cut down to one pint per 100 miles, perhaps its representative will enlighten us on the point. Carbonisation has been noted by everybody and has been accepted as a necessary evil of mechanical lubrication; this means that all engineers have not been getting the best out of this apparatus since its introduction. Further, if a consumption of one pint per 100 miles (quoted by Mr. Rliss) is sufficient with this apparatus under exacting conditions, it would have been more to the point for the lubricator people to show what their apparatus was capable of before introducing a fresh complication.

No member referred to definite experience of the lubrication of superheater engines equipped with slide valves. This question would have provided a discussion of interest, in that the information obtained would facilitate the conversion of older engines to superheaters without the necessity of new values and cylinders or alterations to valve gear. May I hope that some member witb information at his disposal 
will bring this point before the Institution and also state the composition of material used for the valves. In further reply io Messrs. Thomsen and Bliss, I admitted our consumption was high; the reason for this was given in my paper, but we still use less than the L.N.W.R., according to Mr. Dunn's figures. I must add that of two engines working in the same link and using the same oil month in month out, one having a mechanical and the other a hydrostatic lubricator, and on only 9 per cent. less oil consumption in the case of the latter, therc is absolutely no comparison between the two in carbonisation. For the last few months the latter has been running on ordinary cylinder oil at the same rate of consumption without trouble from carbonisation. Labour troubles since October have prevented me from extending this experiment to a mechanical lubricator, but a few years ago on this division ordinary cylinder oil was erroneously supplied to an engine so fitted with the result of badly cut valie liners.

Mr. Bliss further makes a strong point that the feed of the mechanical lubricator is purely in proportion to piston speed and distance travelled, without analysing the matter from all points of view, but Mr. Lelean lortunately deals with it impartially. The answers to the questions put by him depend to a certain extent on how much oil for what percentage of total amount of vil) is fed to the cylinders with steam on. The cylinders certainly require lubrication with regulator shut as they do not get the same benefit from lubricated steam Irom the valies. The necessity for lubrication would increase with the piston speed did the output in horse-power increase in like ratio; but as this is not the case it varies with the mean effective pressure in the cylinders which is the truer measure of the load under which the engine is working. These conditions are, to my mind, aggravated in the case of a superheater engine, and a steam jet is essential. Mr. Lelean, however, only refers to the cylinders, but these remarks are applicable to piston valies and flat vertical values. The conditions are further aggravated in the case of horizontal fial vislies, which we have had great difficulty in lubricating under the influence of high superheat.

Mr. Bliss further seems to think that there is difficulty in obtaining uniformity of feed with the hydrostatic lubricator and that one set of men might use 100 per cent. more pil than others; I would remind him that the margin of oil allowed per trip would not admit of anything like such a yariation in consumption; that we try to instruct our drivers 
and allow for a certain amount of intelligence on their part. On the other hand, the mechanical lubricator is just as open to the same abuse by adjustment of the driving rods in any station.

I understand from Mr. Mannering that the L.B.S.C.R. drives the lubricator from the valve spindle; this makes the feed theoretically proportional to the valve travel and would (assuming regulator opening constant throughout the run) give greater feed with increase of mean effective pressure in the cylinders. Practically this is only true in extreme cases except with friction drive to the lubricator. I note that the same railway leaves the proportion of oil fed to the cylinders and valves to the discretion of the driver, which implies that each man individually is allowed to adjust his own oil regulating plugs. This is ept to give rise to diffculties unless the men are well acquainted with the amount they are cutting down the feed per turn of nut, etc., and prohibits a standard rate of feed. Our plugs are set in the running shed, the lubricator tested for consumption, and they are not allowed to be touched by the engine crews. We have four delivery pipes of a total length of 115 feet. The alteration in rate of feed as influenced by temperature was noted in readings taken by myself under ordinary running conditions and was always confirmed to more or less the same extent by further readings under similar weather conditions.

With regrard to heating of axleboxes, I would refer Mr. Dunn to a letter by Mr. W. G. Landon, in the "Locomotive Magazine" for November, as this might have some bearing on his casc. In place of the simple groove in the box crown I remember seeing a G.W. engine which had boxes provided with two oil grooves parallel to the axle, and taking as a centre the point where a line drawn from the centre of the axle at $45^{\circ}$ on each sids of the perpendicular intersected the circumference of the axle, these being the points at which the box receives its maximum thrust. I was greatly taken with this idea and $I$ was informed that it was standard practice on this line.

Analysis of carbonised deposit on our valves showed 35.67 per cent. of carbonaceous matter. I have no experience of mechanical feed for axleboxes; we rely entirely on syphon feed from a well in the box crown.

I much regret that there was no L.S.W.R., G.W.R., or G.S.W.R. (Ineland) member present to state his case in defence of the hydrostatic hubrieator as used by these lines; 
for, valuable and interesting as Mr. Thomsen's remarks are, a member actually in touch with locomotives day by day could enter upon a much more detailed and practical discussion than I can hope to do writing from some 7,000 miles. away.

The President reminds me that with the introduction of the anti-carboniser, the mechanical lubricator should become the more successful of the two. I have had no experience of this apparatus, but judging from the discussion, I feel that there is room for improvement, and that an automatic device for shutting off steam from the jets when the engine is standing should be a necessity. The mechanical lubricator, however, sprang into prominence and favour long before the introduction of the anti-carboniser and I am still wondering with Mr. Clayton why British engineers did not yo on with the improvement of the sightfeed lubricator on the true hydrostatic principle. I am also without knowledge of the Intensifore Lubrioator (beyond having seen the drawings), and it would be very interesting to hear expert G.C. Running Department opinion on its. performance in every day work.

On the subject of working full regulator, I must admit the remarks were rather a surprise to me. Under our own service conditions the full regulator men show up very well on the coal sheet, and in support of $\mathrm{my}$ previous contention perhaps I may be forgiven for quoting verbatim (if only for the sake of argument) a paragraph from a report on fuel economy by a Select Committee of the American Master Mechanics' Association in May, 1915, as I have the pamphlet bv me.

"That the method of handling the throttle on superheater locomotives is of more importance than is generally realised, has been shown by the answers given to our question as to the proper method of using the throttle on superheater locomotives. The best results are secured by the use of a full throttle opening, with reverse lever control as far as service conditions will permit, the exceptions being: When starting a train, when using a very small quantity of steam while running at high speed on low grade or level track, and when drifting. Actual test data prove conclusively that greater economy of fuel and water is obtained by operating with a full throttle opening and a short cut-off than with a partial throttle opening and a longer cut-off. The figures shown in the following table were drawn from the Report of Tests of a Class E6S passenger locomotive at 
Altoona, which forms a part of the 1913 Proceedings of this Association :-

Lb. per I.H.P. per hour at 1,500 H.P. Partial Full throttle. throttle.

\begin{tabular}{|c|c|c|c|c|c|c|}
\hline \multirow{4}{*}{$\begin{array}{l}\text { Dry coal, lb. } \\
\text { Steam, lb. }\end{array}$} & \multirow{3}{*}{\multicolumn{2}{|c|}{$\begin{array}{r}1 . \\
40 \% \\
\text { cut-off. } \\
2.52\end{array}$}} & \multirow{3}{*}{$\begin{array}{c}2 . \\
30 \% \\
\text { cut-oif. } \\
2.25\end{array}$} & \multirow{2}{*}{$\begin{array}{c}3 . \\
20 \% \\
\text { cut }-0 \text { off. }\end{array}$} & \\
\hline & & & & & & 3 \\
\hline & & & & & $\begin{array}{c}1 . \\
19.8\end{array}$ & \\
\hline & & 18.9 & $17 \cdot 5$ & 15.8 & 16.4 & 0.7 \\
\hline
\end{tabular}

"The Committee is of the opinion that, to secure the greatest economy in the use of fuel and water, superheater locomotives (if not all locomotives) should be operated with a full throttle and reverse lever control at all times when consistent with operating conditions."

In conclusion, I beg to express my thanks to the President and all members present for the kind reception accorded to my paper.

\author{
APPENDIX I. \\ Wakefield's Anti-Carboniser. \\ (Figs. 1, 2, and 3).
}

Oil from the Wakefield mechanical lubricator enters at $A$ and is forced past the plunger check valve $B$ and through the passage $C$, when it comes into contact with the steam jet.

Steam enters the anti-carboniser at $D$ and branches along the passage $E$ which communicates with each of the outlets F. A check ball valve is provided at $G$ which prevents the oil and steam from traversing in a reverse direction.

It will be seen that the point of contact of the oil and steam is in the small space or cavity $H$. The oil and steam together then pass through the baffle $J$ and so to the outlet F.

The object of the baffle is more thoroughly to mix the oil and steam which would not, of course, so thoroughly mix were they merely to pass out through a plain hole.

The steam from the boiler, which enters the anticarboniser at $D$, is controlled by the Wakefield patent automatic steam valve. This latter apparatus should preferably be fitted in the driver's cab, and is so constructed that it automatically opens and admits steam to the anti-carboniser immediately the driver opens the regulator. 
The valve does not, however, automatically close when the regulator is shut, as it is most important that steam should be blowing through to the anti-carboniser when the locomotive is drifting, as undoubtedly it is then that carbonisation is most likely to take place, if the oil, in its pure state, is forced on to the dry hot surfaces without having the benefit of the scavenging effect of the steam.

The drawing shows a two-way anti-carboniser, but it can be made with any reasonable number of feeds.

The oil test plug shown at $\mathrm{K}$ is for the purpose of testing the oil flow from the mechanical lubficator.

The usual practice (assuming that a six-way anti-carboniser is required) is to fit a three-way anti-carboniser on each side of the locomotive. The steam from the automatic steam valve is carried in one pipe to a Doint just behind the front tubeplate, where it divides, one branch leading to each anti-carboniser.

\section{APPENDIX II.}

\section{Great Westems Railway.}

Description of aNd Instrections for Working Swindor Triple Sight-Fend Llbricatoh.

(Figs. I1, 12, and 13).

By this lubricator the oil fed by drops through the usual sight-feeds is conveyed and distributed to the valves and cylinders by means of an auxiliary steam pipe, thin. bore.

The arrangement is such that the first steam to reach the cylinders on starting the engine comes through this auxiliary steam pipe, and brings a supply of oil with it.

When coasting, or drifting, a little steam and oil must be fed to the cylinders without moving the handle far enough to open the "jockey" or regulator. The regulator handle should be first shut and then opened until the pin fitted to the pointer engages in the catch provided on the stuffing box. This gives the correct position for drifting.

When the regulator handle is fully closed on its stop the lubricator will feed a few drops and then stop altogether.

This small quantity of oil will remain in the pipes ready to be distributed to the cylinders when the engine is again started.

With this lubricator, oil will not run out of the cylinder cocks unless too much is being used. 


\section{WorkING.}

The regulator jockey does not admit steam to the cylinders until the pointer on the regulator handle has been moved about fin. from its stop, but the valve $W$ is arranged to open just before this occurs, when the pin on the pointer of regulator handle engages in the catch on the stuffing box. The lubricator feed will not increase and clog the glasses when the regulator is closed, as valve $W$ closes with it and cuts steam off from the auxiliary pipe $F$.

Oil is fed from the sight-feeds through the oil pipe $D$ to valve $W$. Steam through the pipes $E$ and $E_{1}$ picks the oil up from valve $W$ and carries it through the pipe $F$ to the oil distributor $O$ in the smokebox. From $O$ distributing pipes $\mathrm{P}$ conver it to the steam pipes.

Oil is fed to the regulator by displacement through the pipe $S$ direct from the lubricator in the usual way.

To warm the oil in very cold weather, steam may be passed through the body of the lubricator by opening cock M. It is not necessary to keep this cock fully open, and it should only be used when the oil is too thick to feed.

\section{INSTRUCTIONs.}

Stop valves $J$ and $J_{1}$ should always be closed when the engine is off duty, but it is very important that they should be fully open before the engine is moved.

To fill the lubricator, turn the handle of cock $U$ of condensing pipes to position marked "off," then open drain cock $Q$ and run water off, avoiding any waste of oil. Close the drain cock and fill with oil through the filling plug $R$. The oil should preferably be warmed a little as it expands greatly when heated. If for any reason there is not sufficient oil to fill the lubricator, make up with water, replace plug and see that the handle of three-way cock $T$ is pointing vertically downwards. It is very important that the lubricator should be absolutely filled. Turn the handle of cock $U$ to the open position, and the lubricator is ready for work. The smallest quantity of oil should be fed through the regulator, a few drops occasionally are all that is required.

When the engine has been out of use for a time it is desirable to start the cylinder feeds before moving. This will well lubricate the valves and pistons when the engine starts.

The left hand sight-feed feeds the regulator and the right hand feeds the cylinders. The middle feed is spare, 
and is so marked. It can be used in emergency, when the cylinder glass breaks or clogs. Should the regulator glass break or clog, the glass must be changed, as the spare feed cannot be switched on to it. When the handle $\mathrm{L}$, controlling the middle feed, is in the "straight out " position the feed does not work, but it may be switched on to the cylinder by moving handle $L$ through an angle of 45 degrees into the position marked on lubricator. The regulating spindle of the broken or clogged glass must first be shut.

Should valve $W$ stick up, stop valves $J$ and $J_{1}$ and needle valve of lubricator must be closed when valve $W$ may be examined. Do not adjust the oil feed more than necessary. It should vary but very little for different openings of the regulator. Examine glasses about once a fortnight, as they are liable to corrode about the packing in this time. Glasses are filled with water by removing the top plug in the usual way. The pins and rubbing surfaces controlled by regulator handle should be oiled occasionally.

In case of a burst condensing pipe $\mathrm{C} \mathrm{C}$, the handle of three-way cock $T$ must be moved through an angle of 90 degrees toward the sound pipe; this shuts off the defective pipe and supplies steam to the other. The handle of cock $U$ should be moved to the position marked on lubricator to bring the other pipe into action.

To shut off both condensing pipes the handlc of cock $T$ should point upwards in a vertical direction.

In frosty weather run all water out of lubricator and condensing pipes by cock $Q$ before putting engine away.

Do not adjust regulator sight-feed until regulator is at least half open, or it will feed too fast as you open regulator.

After filling lubricator the warming cock $M$ must never be opened until cocks $U, T, J$ and $J$, have been opened, or the lubricator will burst by the expansion of the oil. 


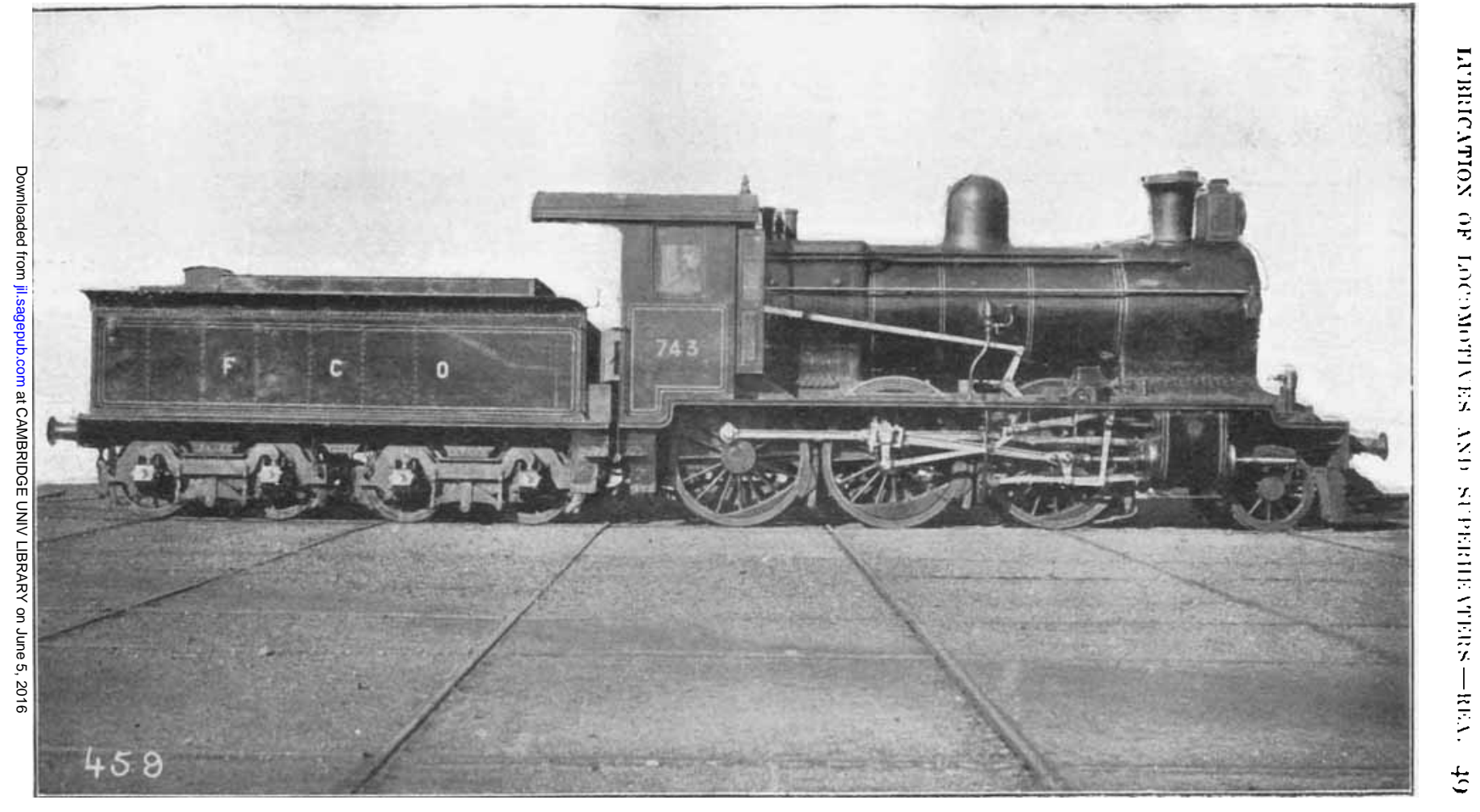

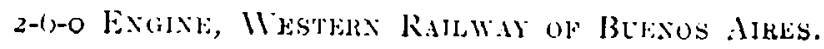



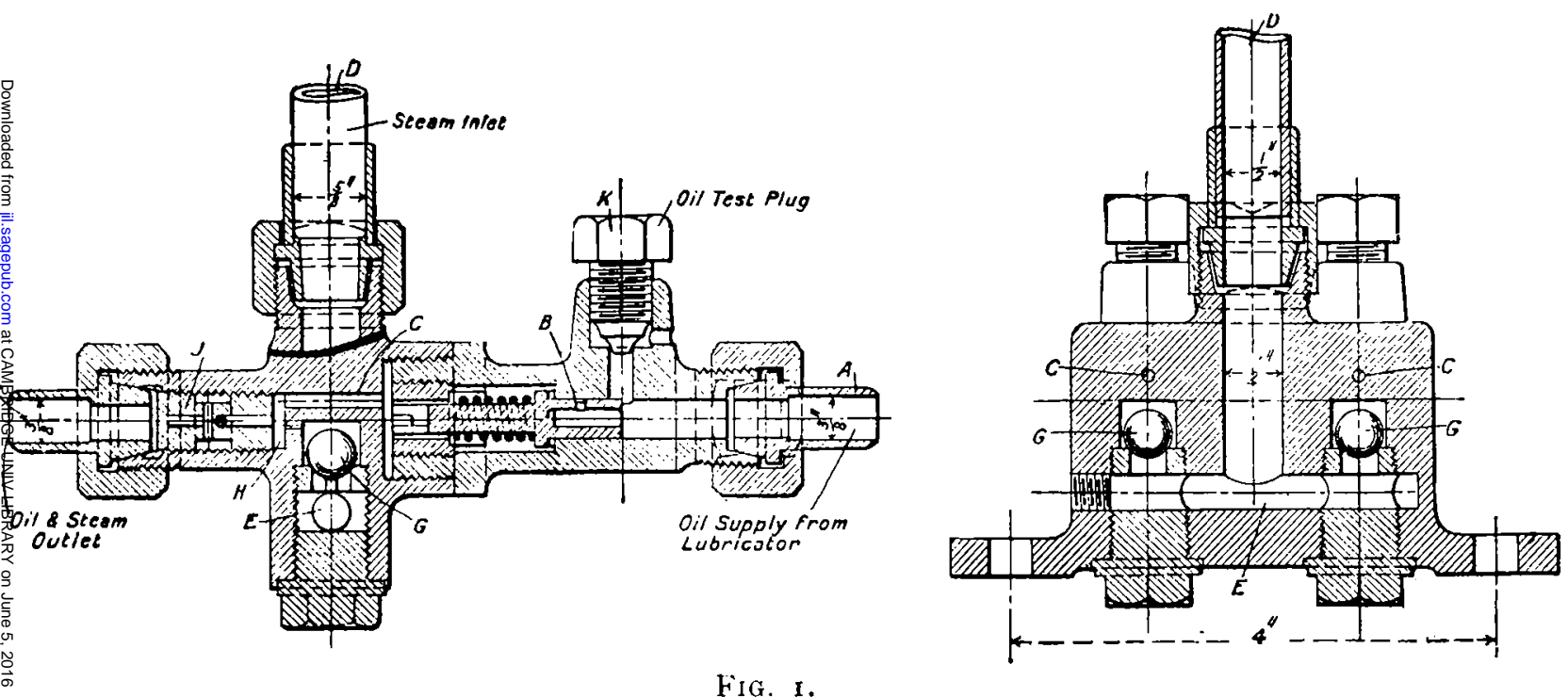

Fig. I.

WAkEFiet dNTI-CaRBoNiser.

Mr. J. Bliss. 


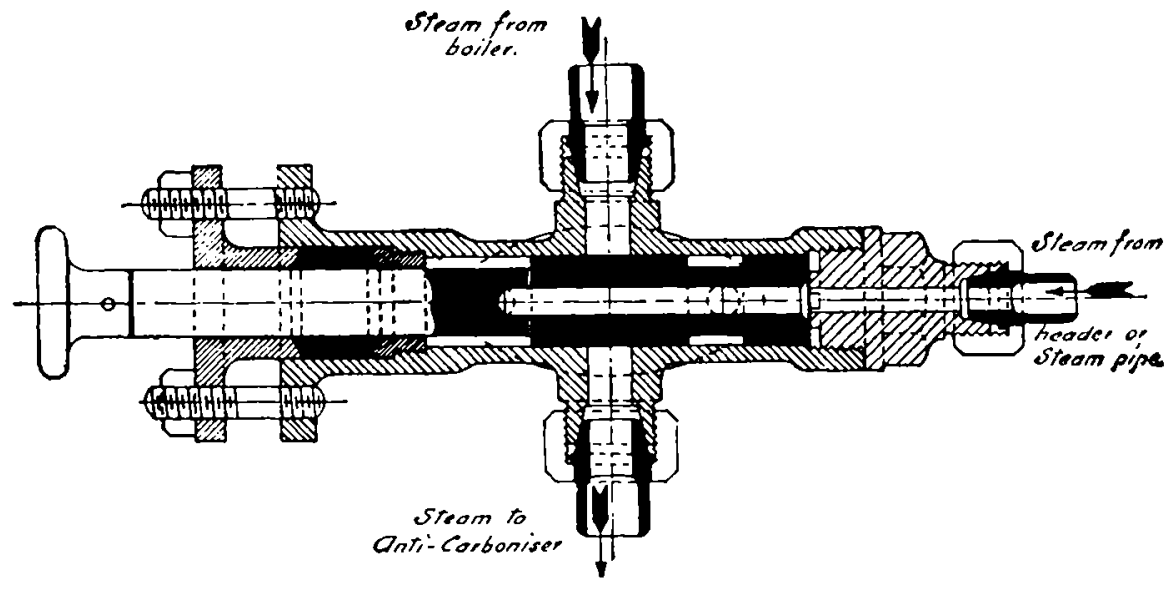

FIG. 2.

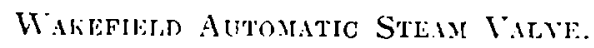

Mr. J. Bliss. 


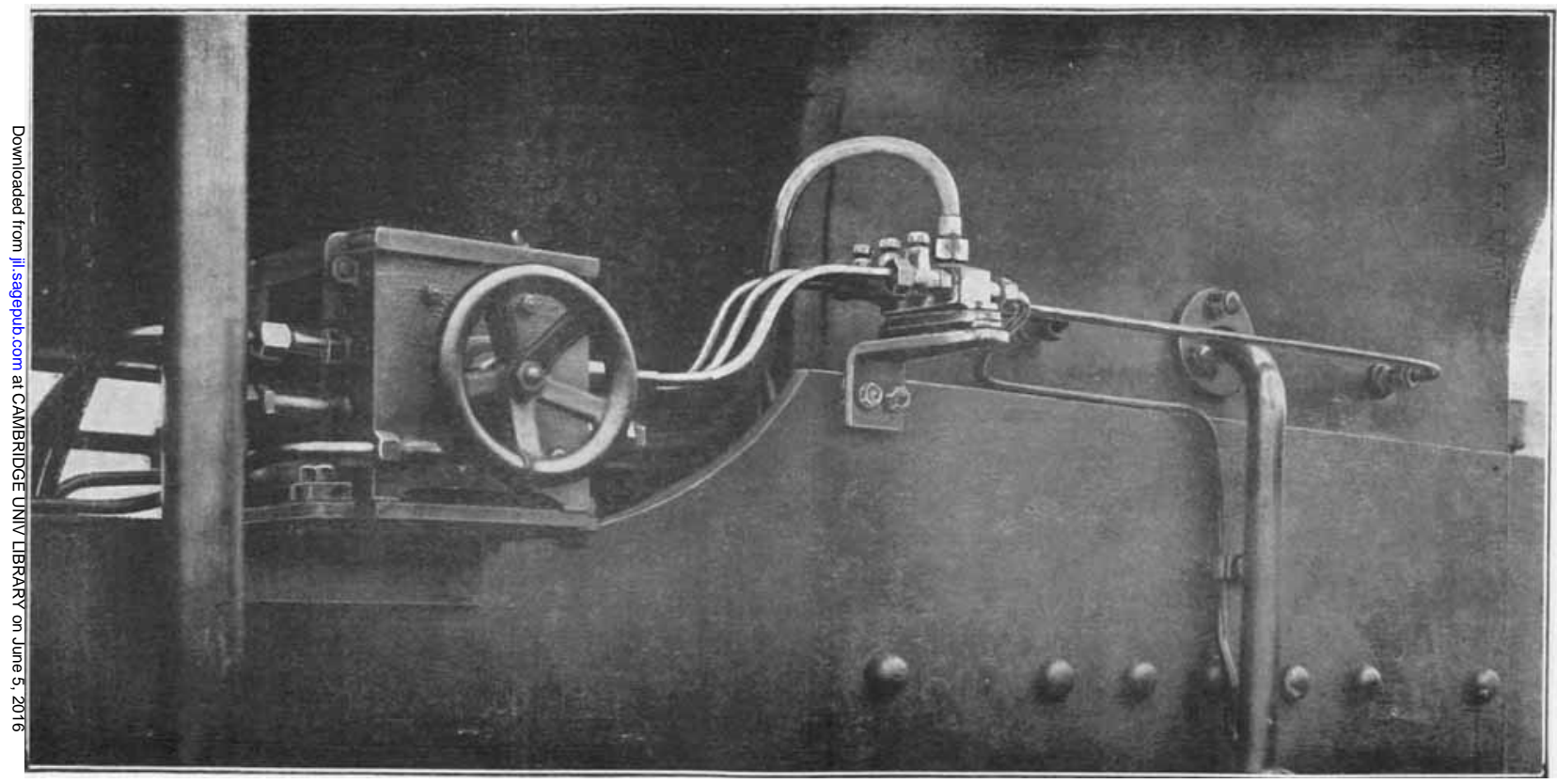

Fir. 3 .

Mr. J. Bliss.

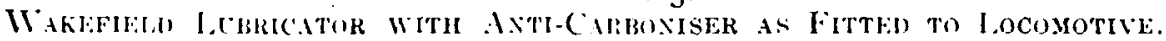



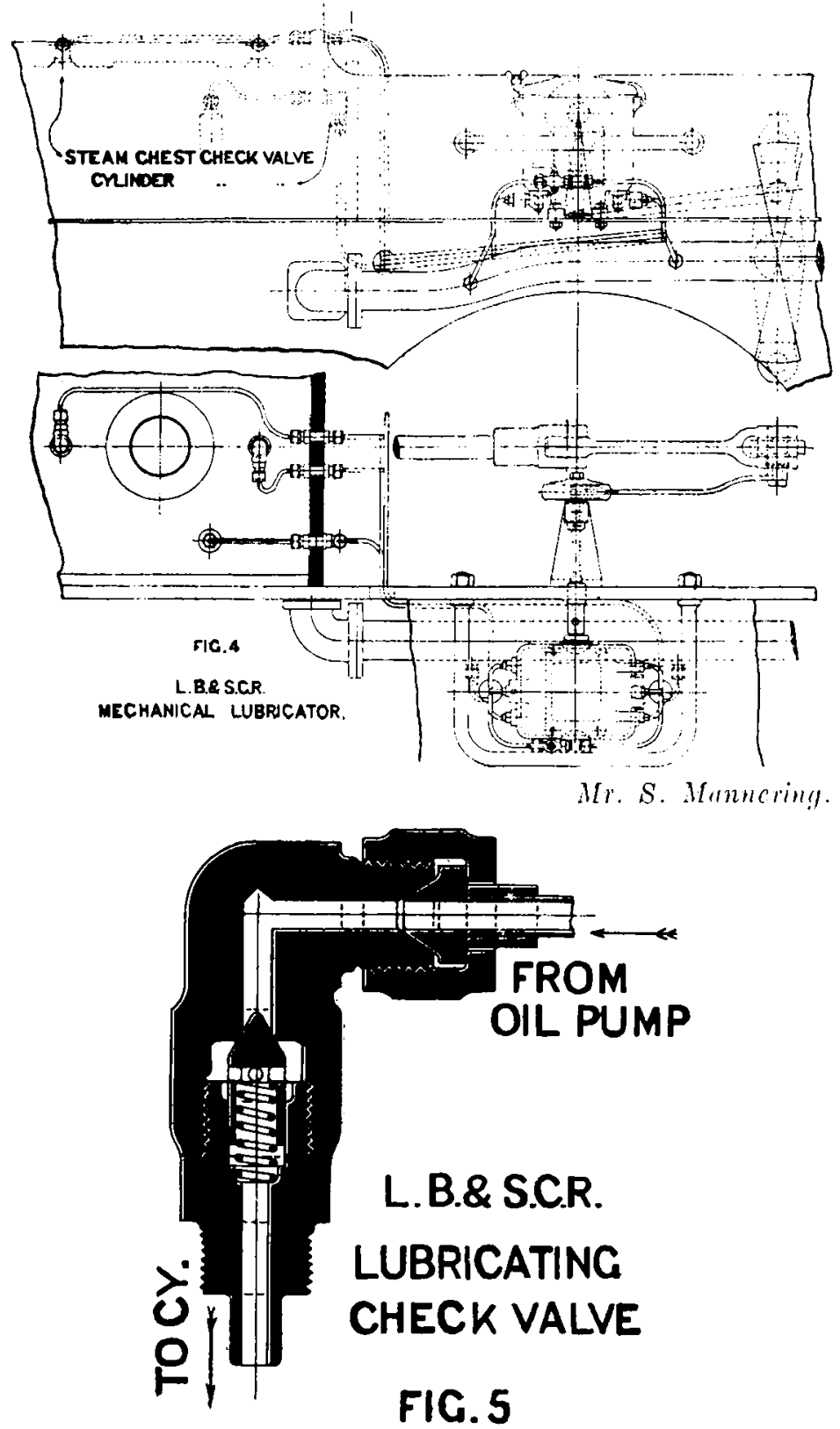

Mr. S. Mannering. Downloaded from jil.sagepub.com at CAMBRIDGE UNIV LIBRARY on June 5, 2016 

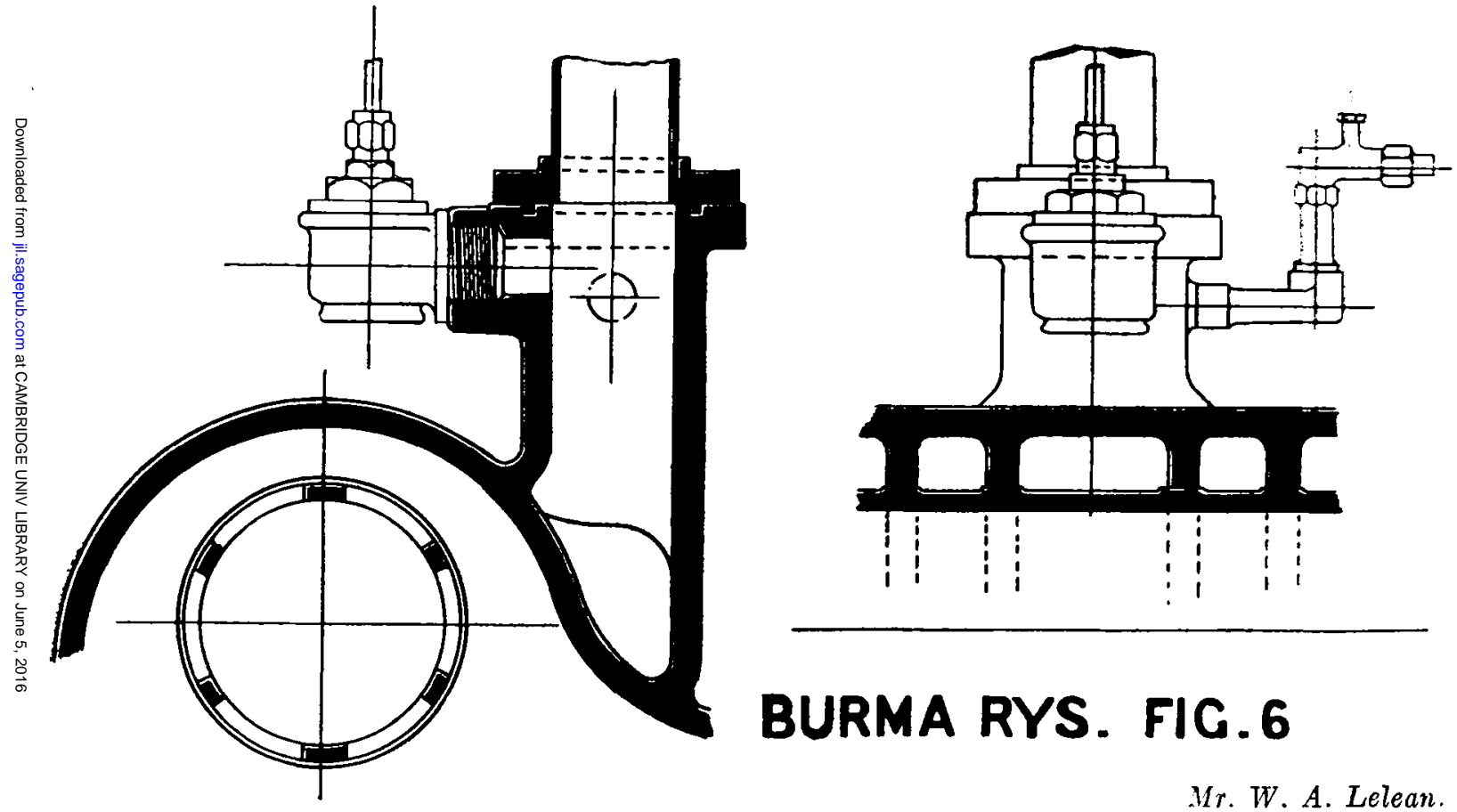

BURMA RYS. FIG. 6

Mr. W. A. Lelean. 


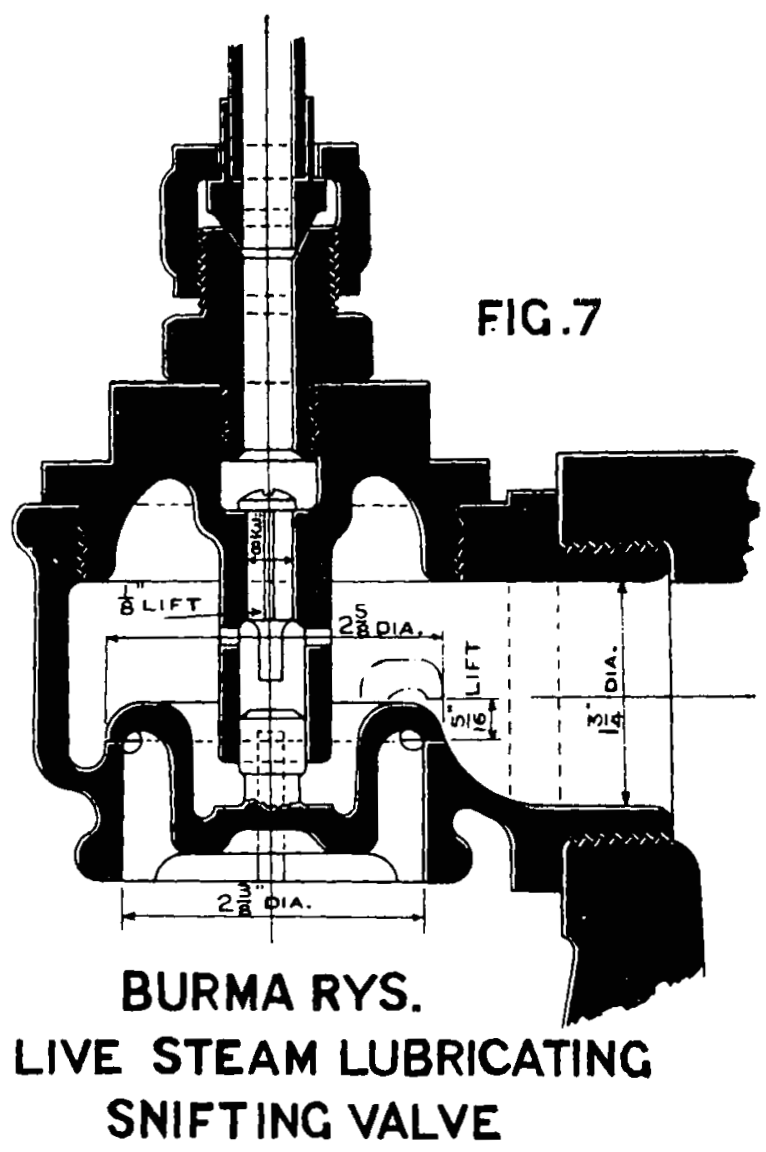

Mr. W. A. Lelean. 


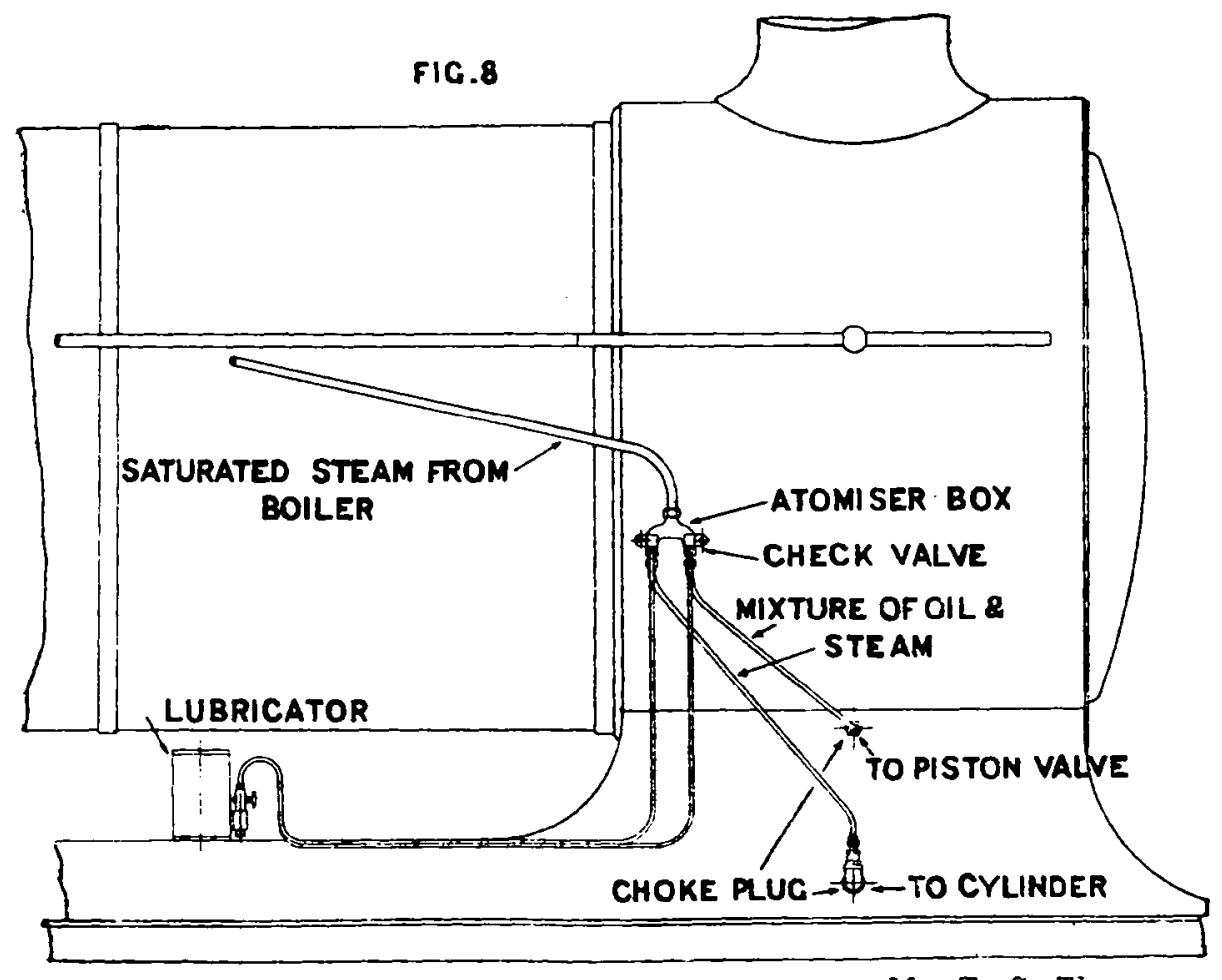




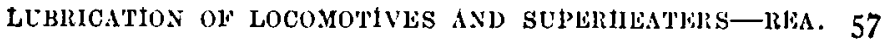

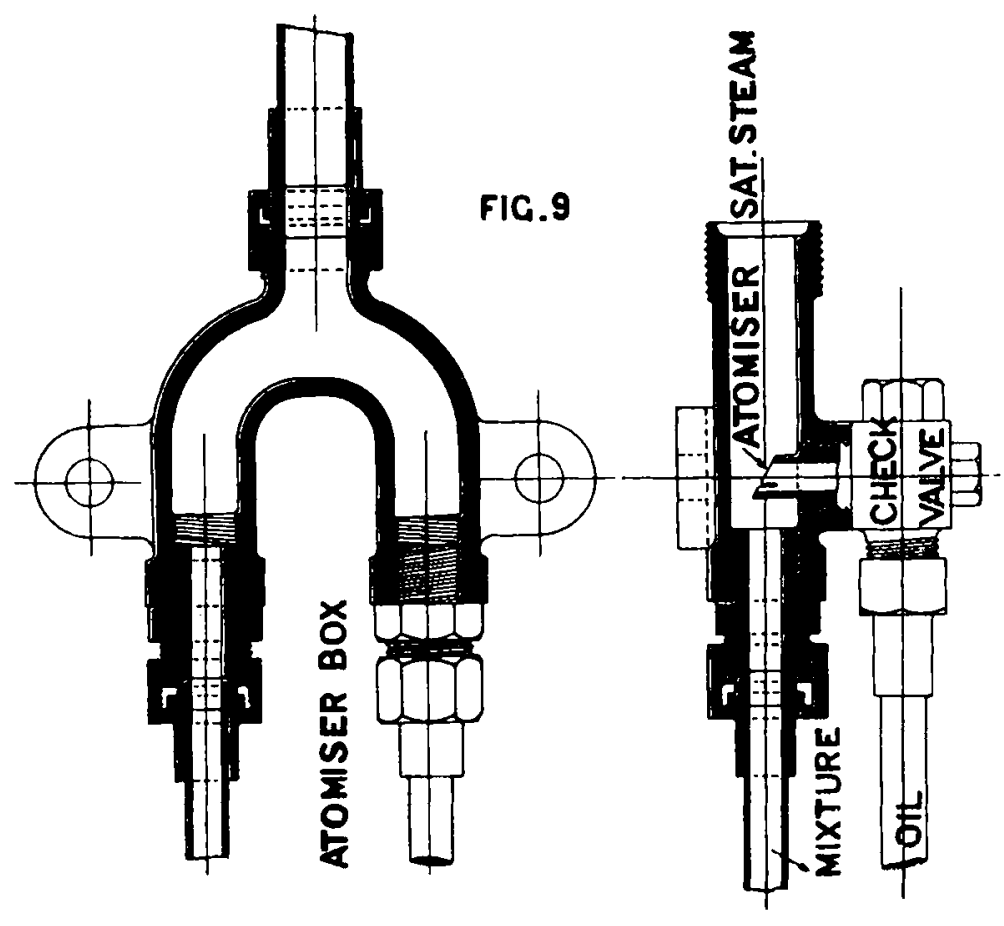

Mr. T. C. Thomsen. 


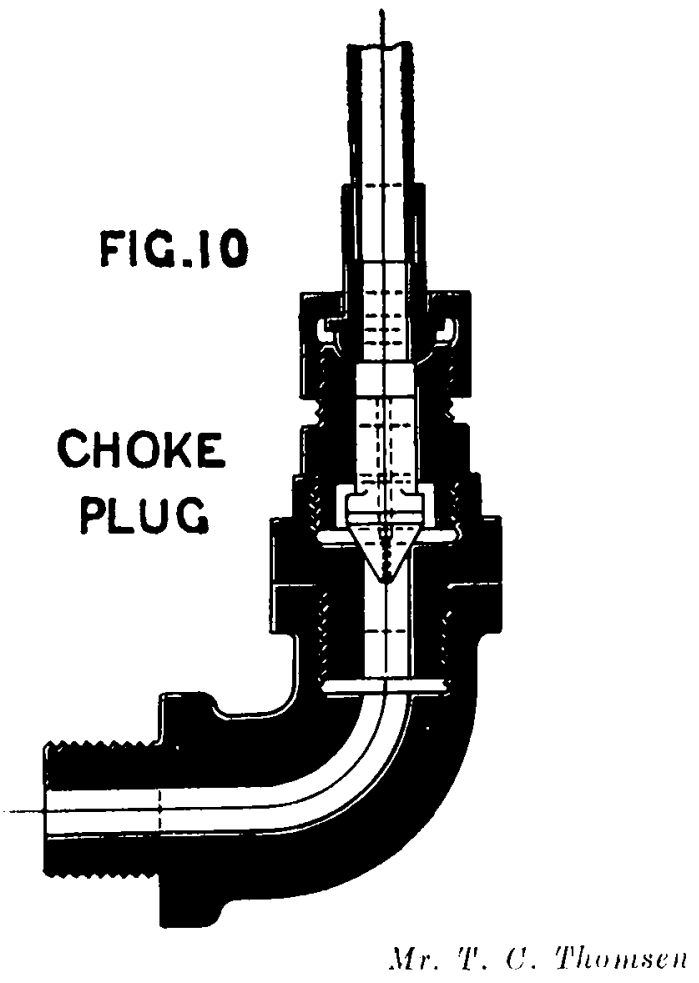




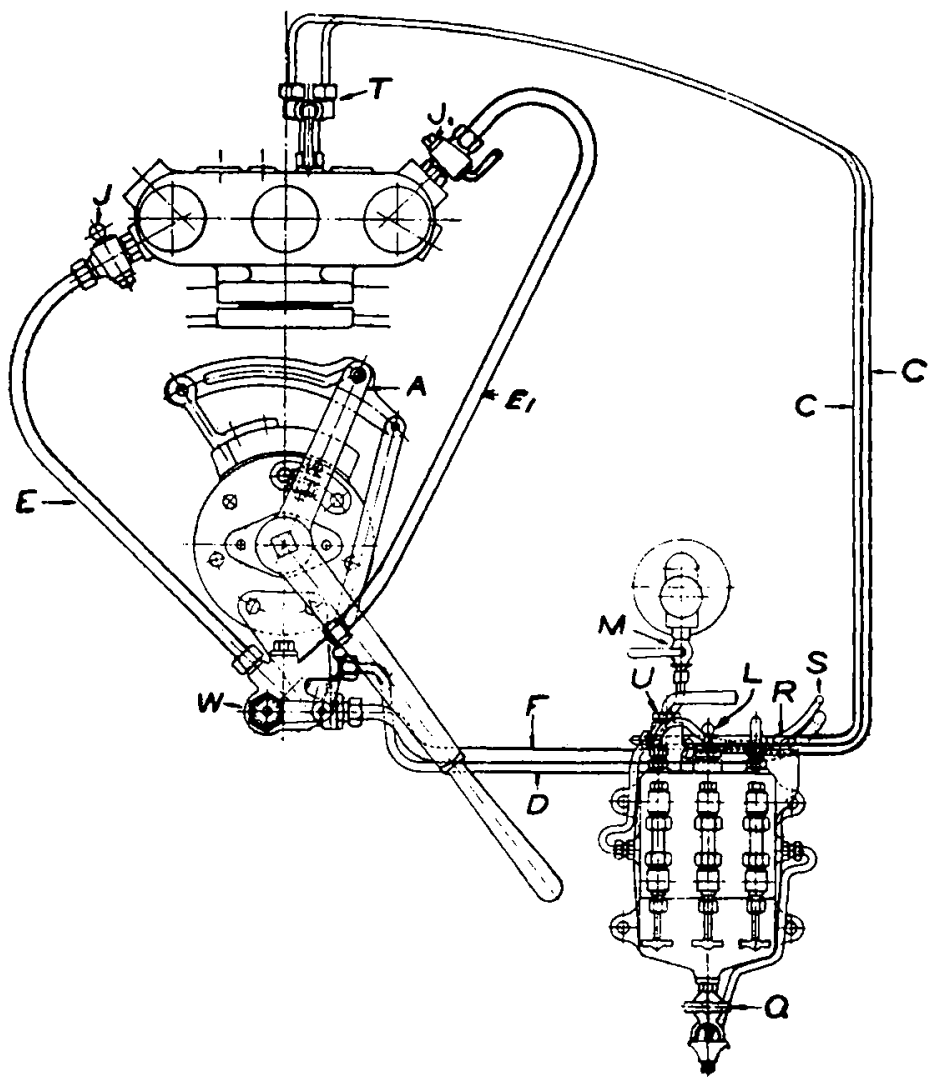

FIG. II.

Mr. G. F. Burtt. 
6o JOCRTAL OF TILE INST' OF LOCO. ENGINERRS.

III i. I 2 ,

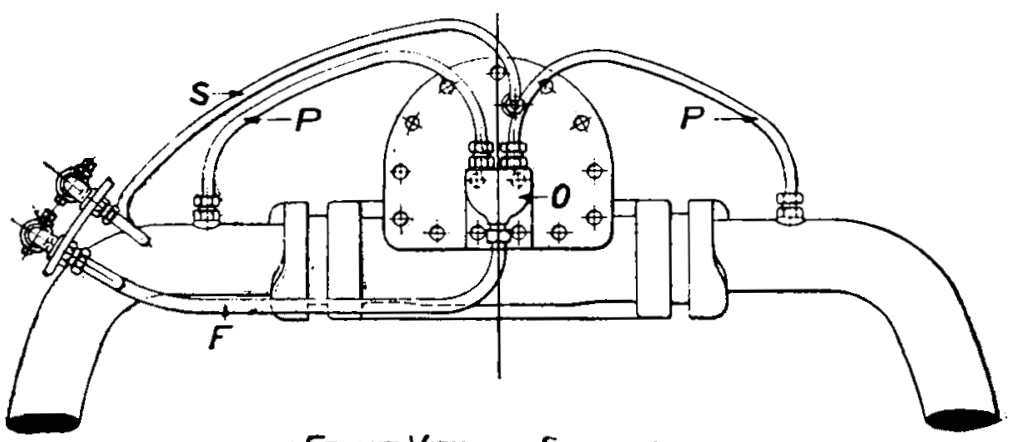

FRONT VIEW - SMOKEBOX -

-- TWO CYLINDER ENGINES WITHOUT SUPERHEATER -

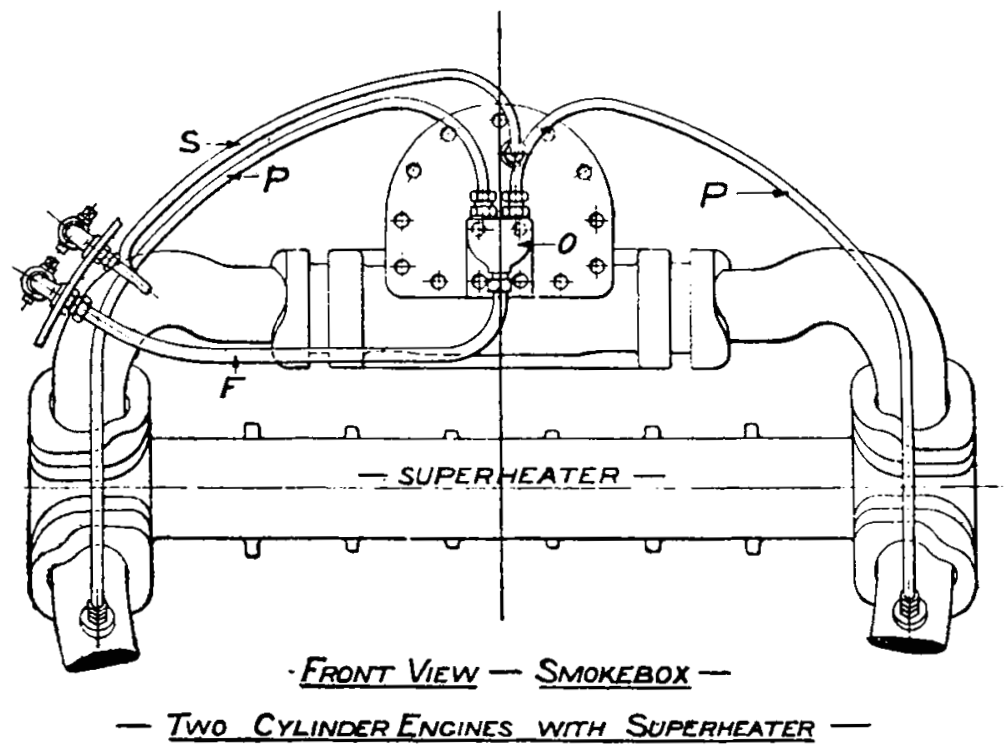

FIG. I3.

Mr. G. F. Burtt. 